Cite this: Phys. Chem. Chem. Phys., 2014, 16, 2072

Received 12th September 2013 Accepted 14th November 2013

DOI: $10.1039 / c 3 c p 53875 c$

www.rsc.org/pccp

\title{
Exploring non-covalent interactions in guanine- and xanthine-based model DNA quadruplex structures: a comprehensive quantum chemical approach $\dagger$
}

\author{
Yevgen P. Yurenko, Jan Novotný, ${ }^{\mathrm{ab}}$ Vladimir Sklenár ${ }^{\mathrm{abc}}$ and Radek Marek*abc
}

\begin{abstract}
The study aimed to cast light on the structure and internal energetics of guanine- and xanthine-based model DNA quadruplexes and the physico-chemical nature of the non-covalent interactions involved. Several independent approaches were used for this purpose: DFT-D3 calculations, Quantum Theory of Atoms in Molecules, Natural Bond Orbital Analysis, Energy Decomposition Analysis, Compliance Constant Theory, and Non-Covalent Interaction Analysis. The results point to an excellent degree of structural and energetic compatibility between the two types of model quadruplexes. This fact stems from both the structural features (close values of van der Waals volumes, pore radii, geometrical parameters of the $\mathrm{H}$-bonds) and the energetic characteristics (comparable values of the energies of formation). It was established that hydrogen bonding makes the greatest ( $\sim 50 \%)$ contribution to the internal stability of the DNA quadruplexes, whereas the aromatic base stacking and ion coordination terms are commensurable and account for the rest. Energy decomposition analysis performed for guanine (Gua) and xanthine (Xan) quartets B4 and higher-order structures consisting of two or three stacked quartets indicates that whereas Gua structures benefit from a high degree of $\mathrm{H}$-bond cooperativity, Xan models are characterized by a more favorable and cooperative $\pi-\pi$ stacking. The results of electron density topological analysis show that $\mathrm{Na}^{+} / \mathrm{K}^{+}$ion coordination deeply affects the network of non-covalent interactions in Gua models due to the change in the twist angle between the stacked tetrads. For Xan models, ion coordination makes tetrads in stacks more planar without changing the twist angle. Therefore, the presence of the ion seems to be essential for the formation of planar stacks in Xan-based DNA quadruplexes. Detailed study of the nature of ion-base coordination suggests that this interaction has a partially covalent character and cannot be considered as purely electrostatic. Investigation of the $\mathrm{H}$-bond and ion-base coordination strengths by various independent approaches agrees well with the results of QTAIM analysis.
\end{abstract}

\section{Introduction}

Non-covalent interactions, including ion-ion, dipole-dipole, ion-dipole, and dispersion interactions, hydrogen $(\mathrm{H})$ bonding, steric clashes (SC), are ubiquitous forces that play a paramount role in all areas of biology and nanoscience. ${ }^{1-3}$ The most

\footnotetext{
${ }^{a}$ CEITEC - Central European Institute of Technology, Masaryk University,

Kamenice 5/A4, CZ - 62500 Brno, Czech Republic. E-mail: rmarek@chemi.muni.cz

${ }^{b}$ National Center for Biomolecular Research, Faculty of Science,

Masaryk University, Brno, Czech Republic

${ }^{c}$ Department of Chemistry, Faculty of Science, Masaryk University, Brno, Czech Republic

$\dagger$ Electronic supplementary information (ESI) available: Figures with spatial structures of two and three stacked tetrads as well as tables with the values of the van der Waals volumes and more detailed characteristics of individual noncovalent interactions. See DOI: 10.1039/c3cp53875c
}

striking evidence of the importance of non-covalent interactions is their significance in governing spatial structures and driving folding processes in nucleic acids, proteins, and their assemblies. Moreover, an intricate interplay of various noncovalent interactions determines, to a great extent, the course of all biochemical processes inside a living cell, ${ }^{2}$ where the mutual recognition of biomolecules via non-covalent contacts occurs. In particular, a comprehensive study of non-covalent interactions would be beneficial for understanding the polymorphism and heterogeneity of DNA, since non-covalent forces that govern the different forms of DNA are not completely understood. Although experimental studies provide valuable insights into the internal characteristics of non-covalent forces, they are usually hindered by complications arising from environmental effects, as well as competing non-covalent interactions. Therefore, quantum chemistry investigations of model systems 
can be considered as a unique approach that paves way for understanding the role of the main non-covalent forces arising in the forms of DNA and the transition states between them.

Among the possible DNA structures, guanine quadruplexes (G-quadruplexes) deserve special attention. They are formed in guanine-rich sequences that occur frequently in eukaryotic genomes. ${ }^{4}$ It should be noted that direct evidence for the formation of G-quadruplexes in vivo was absent for a long time. Only very recently, have Biffi et al. engineered an antibody that binds specifically to G-quadruplex structures and enables the direct visualization of G-tetraplex sites in chromosomes. ${ }^{5}$ In addition, the indirect data also prove convincingly the supreme biological importance of G-quadruplexes. For instance, proteins that can bind to G-quadruplexes have been observed, ${ }^{6}$ as well as helicases ${ }^{7}$ and nucleases ${ }^{8}$ that act specifically on these structures. However, the most striking fact is that quadruplexes are most likely present in the telomeres ${ }^{9}$ of eukaryotic cells. A link between immortality and telomere maintenance in stem and germ line cells has been demonstrated. ${ }^{10}$ The proliferating cancerous cells are immortal due to the high activity of the telomerase enzyme maintaining the length of the telomeres. Whereas single-stranded DNA is a telomerase substrate, G-quadruplex DNA is not. In this respect, numerous strategies for the inhibition of telomerase, based on folding single-stranded DNA to G-quadruplexes, have been proposed. ${ }^{11,12}$

The basic unit of G-quadruplexes is a guanine tetrad (G-tetrad), also known as a guanine quartet or simply G-quartet (Fig. 1). Guanine (Gua) moieties in quadruplexes are held together by the following main types of non-covalent interactions: ${ }^{13}$ (a) hydrogen bonding $(\mathrm{NH} \cdots \mathrm{O}, \mathrm{NH} \cdots \mathrm{N})$ is responsible for assembling four guanine units into the G-tetrad; (b) stacking interactions between individual tetrads enable the formation of higher assemblies (G4) (c) coordination of monovalent ions $\left(\mathrm{Na}^{+}, \mathrm{K}^{+}\right)$, which are typically located in the inter-base regions of the quadruplex pore. ${ }^{14}$

Several theoretical approaches based on ab initio quantum chemical calculations, ${ }^{15-26}$ as well as on regular and adaptive biasing force molecular dynamics simulations (ref. 28-33 and references therein), were used to study the structure and energetics of nucleic acid quadruplexes. These studies revealed important features of the non-covalent interactions in G-quadruplex building blocks. For instance, Louit et al. ${ }^{17}$ analyzed the Hoogsteen and bifurcated H-bonding networks in G-quartets using Quantum Theory of Atoms in Molecules (QTAIM) and established that the Hoogsteen hydrogen-bonding pattern benefits more from cooperativity than the bifurcated one, which is evident from the topological characteristics of the bond critical points (BCP). Recently, it has been shown ${ }^{18}$ that the H-bond cooperativity in G-quadruplexes originates from the charge separation in the $\sigma$-electron system and not from the resonance assistance of the $\pi$-electron system. The substantial values of the calculated trans-H-bond $J$-coupling constants ${ }^{\mathrm{h} 2} J_{\mathrm{N} 2 \mathrm{~N} 7}$ and ${ }^{\mathrm{h} 3} J_{\mathrm{N} 1 \mathrm{C} 6}$ and their correlation with the geometric characteristics of the H-bonds ${ }^{15}$ suggest an important covalent contribution to the H-bonding in G-tetrads. Some authors have considered coordination with metal ions to be essentially covalent, ${ }^{34}$ whereas other studies ${ }^{16,35}$ view it as purely electrostatic in nature. Recently, the influence of different stacking patterns on the stability of stacked G-quartets has been estimated. ${ }^{25}$ However, the nature of the $\pi-\pi$ stacking in G-quadruplexes and its contribution to their stability remain largely unknown.

In addition to their pharmacological applications, DNA quadruplexes and their modified forms ${ }^{36}$ are investigated and
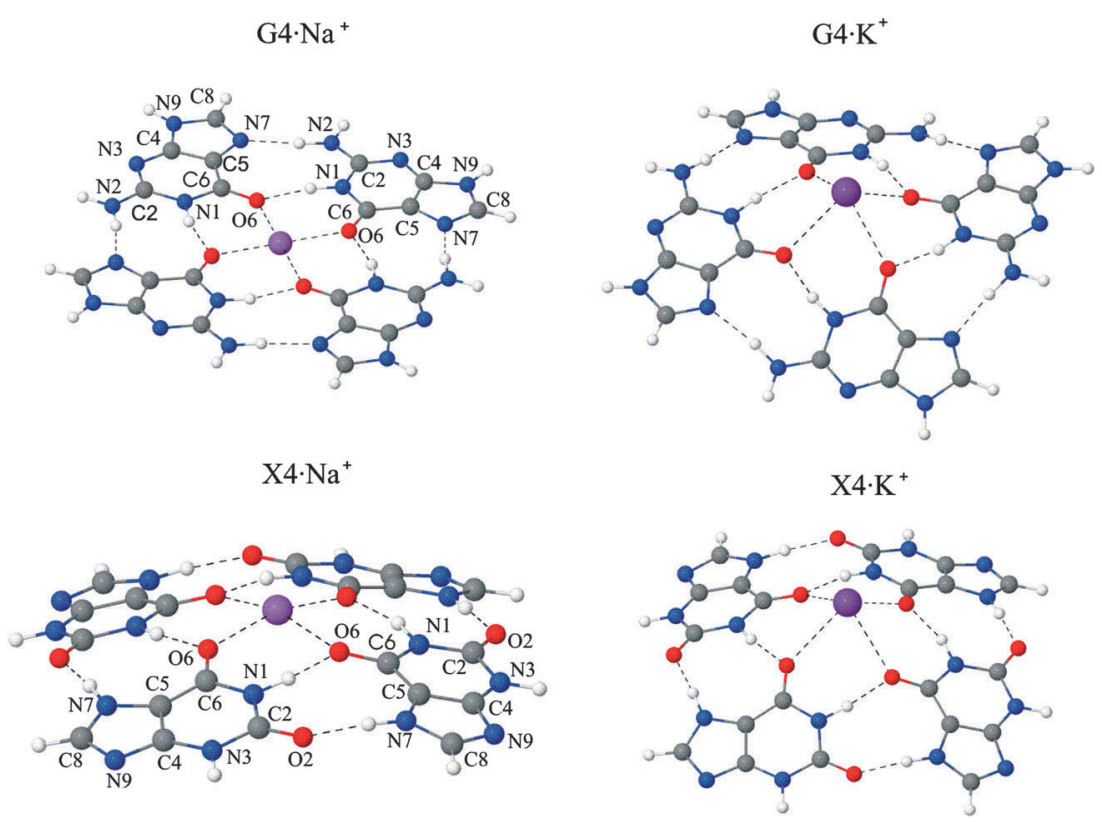

Fig. 1 Spatial structures of Gua and Xan tetrads with sodium and potassium ions as optimized in TURBOMOLE at the BLYP-D3/def2-TZVPP level of theory. Dotted lines denote non-covalent interactions ( $\mathrm{H}$-bonds and ion-base coordination) identified by QTAIM analysis and the atom numbering corresponds to standard nucleic acid nomenclature. ${ }^{74}$ 
designed as building blocks for materials science, biosensors, and nanotechnology. ${ }^{14}$ It should be mentioned that natural G-quadruplexes can be used in the above-mentioned applications. However, chemical modifications of the nucleobases and/or a sugar-phosphate backbone are needed to improve or enhance specifically desired quadruplex properties, such as conductivity or the ability to form supramolecular structures. Xanthine ${ }^{26}$ and its 3-substituted derivatives, ${ }^{27}$ as suggested recently, can be considered as promising candidates for quadruplex formation since they are able to form stable base tetrads, as shown by nano-ESI mass spectra, NMR spectroscopy, and quantum chemical computations. Despite the fact that xanthine and its derivatives ${ }^{27}$ are able to form quartets, the latter are different from the corresponding guanine associates in various ways. For instance, the H-bonding network in xanthine quartets shows little or no cooperativity as compared to G-tetrads. ${ }^{18}$ In our recent work, ${ }^{37}$ the idea of a xanthine scaffold was extended to the construction of artificial N3-xanthosinemodified DNA quadruplexes. The results of molecular dynamics simulations indicate several differences between guanine-based and N3-xanthine-modified DNA quadruplexes, such as preferred conformational states of the sugar-phosphate backbone and iontransporting barriers and mechanisms. In spite of these differences, our simulations ${ }^{37}$ demonstrate the considerable stability of xanthine quadruplexes and imply a good structural compatibility of the xanthine and guanine tetrads in the DNA quadruplexes.

In this paper, we aim to shed light on the electronic nature and intrinsic characteristics of the non-covalent interactions in guanine- and xanthine-based quadruplexes (H-bonding, aromatic $\pi-\pi$ stacking, and metal ion-base coordination). Using simple molecular models, we apply a large arsenal of current state-of-theart quantum chemical techniques including Bader's QTAIM theory, ${ }^{38}$ Natural Bond Orbital (NBO) analysis, ${ }^{39}$ Energy Decomposition Analysis (EDA), ${ }^{40}$ Non-Covalent Interaction (NCI) plots, ${ }^{41,42}$ Grunenberg's compliance constants theory, ${ }^{43,44}$ and charge analyses. We aim to answer the following questions: (i) to what degree guanine- and xanthine-based model quadruplexes are structurally complementary; (ii) how the H-bonding, stacking, and ion-base coordination influence the formation energies of model structures; (iii) what are the fundamental physicochemical forces that determine the sophisticated network of non-covalent interactions in quadruplex structures; and (iv) what is the electronic nature of the non-covalent interactions in the studied systems and how do these interactions influence each other. For the first time, we identify and characterize individual van der Waals contacts arising in model guanine- and xanthinequadruplexes and evaluate their role in maintaining the quadruplex structures. We also discuss possible trends for introducing modifications into the xanthine base in such a way that the non-covalent interactions in new structures would lead to quadruplexes with improved properties.

\section{Computational methodology}

We used the following molecular models for our investigation: H-bonded base tetrads B4 (B = Gua, Xan); base tetrads with
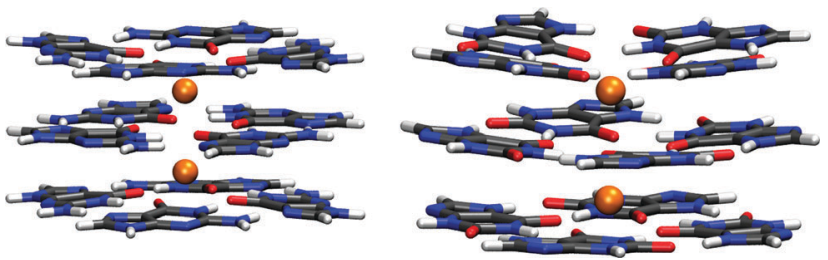

Fig. 2 Optimized structures of Gua (left) and Xan (right) (B4) $)_{3} \cdot 2 \mathrm{Na}^{+}$complexes.

coordinated metal ion $\mathrm{M}^{+}$inside a cavity $\mathrm{B} 4 \cdot \mathrm{M}^{+}\left(\mathrm{M}^{+}=\mathrm{Na}^{+}, \mathrm{K}^{+}\right.$, Fig. 1); two H-bonded tetrads stacked on each other, i.e., $(\mathrm{B} 4)_{2}$; two stacked tetrads $(\mathrm{B} 4)_{2} \cdot \mathrm{M}^{+}$containing a metal ion located in the inter-plane region (Fig. S1 in ESI $\dagger$ ); three base tetrads stacked on each other without metal ions inside the cavity $(\mathrm{B} 4)_{3}$; and three stacked tetrads with one or two metal ions inside the channel, denoted as $(\mathrm{B} 4)_{3} \cdot 1 \mathrm{M}^{+}$and $(\mathrm{B} 4)_{3} \cdot 2 \mathrm{M}^{+}$, respectively (Fig. 2, Fig. S2 and S3 in the ESI $\dagger$ ). Hereafter the general notation for all one-, two-, and three-tetrad models will be B4, $(\mathrm{B} 4)_{2}$, and (B4) $)_{3}$, respectively.

The initial structures of the guanine-based $\mathrm{B} 4,(\mathrm{~B} 4)_{2}$, and $(B 4)_{3}$ complexes were generated from the coordinates obtained from the Protein Data Bank $^{46}\left(139 \mathrm{D}^{47}\right)$. The metal cations were placed manually in such a way that they would closely interact with the internal O6 atoms. The sugar-phosphate backbones and other base pairs were removed. The bond valencies that remained unfilled were each terminated with a hydrogen atom. The xanthine-based models were constructed on the basis of the guanine-containing structures by using the Chimera molecular modeling system. ${ }^{48}$

The starting structures were optimized in the TURBOMOLE V. 6.3 package p $^{49}$ using the BLYP exchange-correlation functional ${ }^{50,51}$ with the recent D3 empirical dispersion correction ${ }^{52}$ and def2TZVPP $^{53}$ basis set. Earlier studies of the systems of stacked nucleobase pairs and quartets showed ${ }^{54}$ that the H-bond and stacking energies obtained with the BLYP functional with dispersion correction are in excellent agreement with the energies (MP2 and CCSD(T) complete basis set limit) obtained from the S22 benchmark database. ${ }^{55}$ The solvent effects in water were estimated using the conductor-like screening model (COSMO) ${ }^{56}$ with the default values of all of the atomic radii. To reduce the time needed to optimize the geometry of the (B4) models, these were pre-optimized in vacuo at the BLYP-D3/def2SVP level of theory. The RI-approximation with the auxiliary basis set def2-TZVPP ${ }^{57}$ was used to speed up the calculation of the Coulombic terms. The DFT grid was defined to be m5. The energetic and geometrical criteria of convergence were set to $10^{-6}$ Hartree and $10^{-3} \AA$, respectively. The formation energies were obtained based on the difference between the energy of the complex and the corresponding optimized components calculated at the same level of theory, i.e., in the general case:

$$
\Delta E_{\text {form }}[\mathrm{AB}]=E[\mathrm{AB}]-E[\mathrm{~A}]-E[\mathrm{~B}]
$$

We did not take the basis set superposition error (BSSE) into account because small BSSE effects are assumed to be absorbed by the D3 empirical potential. ${ }^{18}$ 
Because some of the optimized structures appeared to be non-planar, which is not relevant to real quadruplex systems where stacked tetrads are almost planar, we performed partial optimization of some planar structures to find the energy differences between the non-planar and planar structures, as well as any distinctions in the structural characteristics. The planar forms of tetrad assemblies were prepared from optimized structures by orienting them axially in the $z$-direction and assigning an identical average $z$-coordinate to all of the atoms within a tetrad. To obtain planar structures during optimization, we set a constrained symmetry group $C_{\mathrm{s}}$ for the case of the tetrads B4. For higher order structures, i.e., $(\mathrm{B} 4)_{2}$ and $(\mathrm{B} 4)_{3}$, an additional dihedral angle $\theta=\mathrm{C} 8-\mathrm{N} 1-\mathrm{N} 1-\mathrm{C} 8$ was frozen at $180^{\circ}$ in each stacked tetrad.

Additionally, all model structures were re-optimized by means of the ADF program, ${ }^{58}$ using the same method (BLYP-D3) in combination with an uncontracted polarized triple- $\zeta$ basis set of Slater type orbitals (TZP). The resulting optimized structures were subjected to energy decomposition analysis (EDA) at the same level of theory into electrostatic interaction $\Delta V_{\text {elstat }}$, Pauli-repulsive orbital interactions $\Delta E_{\text {Pauli }}$, attractive orbital interactions $\Delta E_{\mathrm{oi}}$, and dispersion energy $\Delta E_{\text {disp }}$ terms:

$$
\Delta E_{\text {int }}=\Delta V_{\text {elstat }}+\Delta E_{\text {Pauli }}+\Delta E_{\mathrm{oi}}+\Delta E_{\text {disp }}
$$

In eqn (2), the $\Delta E_{\mathrm{oi}}$ term accounts for charge transfer (i.e., donor-acceptor interactions between occupied orbitals on one fragment and vacant orbitals of the other) and polarization (mixing of vacant and occupied orbitals in one region due to the presence of another available region). It should be noted however that molecular orbital-based energy decomposition analysis may overestimate the polarization and charge transfer components. ${ }^{59}$ In the course of energy decomposition we chose molecular regions in a way that allowed separating and evaluating the contribution of a particular type of non-covalent interaction (H-bonding, $\pi-\pi$ stacking, or ion coordination) to the stability of the $\mathrm{B} 4,(\mathrm{~B} 4)_{2}$, and $(\mathrm{B} 4)_{3}$ complexes.

Non-covalent interactions (H-bonds, van der Waals contacts, and ion-base coordination contacts) were initially identified by means of QTAIM ${ }^{38}$ methodology using the AIMAll program. ${ }^{60}$ The presence of a critical point $(3,-1)$ (the so-called Bond Critical Point - BCP), a gradient path between two interacting atoms, and a positive value of the Laplacian of electron density, $\Delta \rho$, were considered as indicators of closed-shell non-covalent interactions (van der Waals contacts, H-bonds, and metal ion coordination). The wavefunctions for QTAIM analysis were calculated in the Gaussian 09 suite of programs ${ }^{61}$ for TURBOMOLE BLYP-D3/def2-TZVPP geometries at the same level of theory (using the BLYP functional and def2-TZVPP basis set imported from the EMSL Basis Set Library). ${ }^{62,63}$

To study the charge transfer property in the interacting orbitals of H-bonds, we resorted to the NBO analysis ${ }^{39}$ implemented in Gaussian, ${ }^{61}$ which interprets the electronic wave function in terms of a set of occupied Lewis and a set of vacant non-Lewis localized orbitals. A second-order Fock matrix analysis was carried out to evaluate the interaction between the donor (i) and acceptor (j) orbitals. The result of such interaction is a migration of the electron density from the idealized Lewis structure into a vacant non-Lewis orbital $\sigma^{*}$. For each donor (i)-acceptor (j) pair, the stabilization energy is calculated as follows:

$$
E_{2}=\Delta E_{\mathrm{ij}}=q_{\mathrm{i}} \frac{F(\mathrm{i}, \mathrm{j})^{2}}{\varepsilon_{\mathrm{j}}-\varepsilon_{\mathrm{i}}}
$$

where $q_{\mathrm{i}}$ is the donor orbital occupancy, $\varepsilon_{\mathrm{j}}$ and $\varepsilon_{\mathrm{i}}$ are diagonal elements, and $F(\mathrm{i}, \mathrm{j})$ is the off-diagonal element of the NBO Fock matrix.

The H-bond energies were evaluated in several ways. The most straightforward method was the use of the EspinosaMolins-Lecomte (EML) ${ }^{64}$ formula based on the electron density distribution at the $(3,-1)$ BCPs of the H-bonds:

$$
E_{\mathrm{HB}}=0.5 V(r)
$$

where $V(r)$ is the value of the local potential energy density (virial field) at the $(3,-1)$ BCPs. Because the formula (4) with the coefficient 0.5 provides only a rough evaluation of the H-bond energy (sometimes smaller values of the coefficient are required to obtain the best fit) ${ }^{65}$ we also applied the relationship suggested by Nikolaienko et al. ${ }^{66}$ to estimate formation enthalpies (in $\mathrm{kcal} \mathrm{mol}^{-1}$ ) for the $\mathrm{NH} \cdots \mathrm{O}$ hydrogen bonds: $E_{\mathrm{NH} \cdots \mathrm{O}}=-2.03+225 \rho^{\mathrm{BCP}}$, where $\rho^{\mathrm{BCP}}$ is the electron density at BCP (in atomic units). This relationship was derived by comparing the QTAIM and vibrational characteristics of $\sim 2901$ conventional hydrogen bonds in 4424 conformers of DNA-related biomolecules. We could not use this alternative methodology to estimate the energies of the $\mathrm{NH} \cdots \mathrm{N}$ hydrogen bonds in Gua-containing structures because, to the best of our knowledge, there are no reliable literature data relating the BCP characteristics of $\mathrm{NH} \cdots \mathrm{N}$ bonds and their enthalpies that have been tested on a large number of $\mathrm{H}$-bonds of this type.

The relative strengths of the $\mathrm{H}$-bonds and ion coordination interactions in the guanine and xanthine tetrads were additionally estimated by using Grunenberg's compliance constants formalism. ${ }^{43-45}$ In contrast to force constants, the numerical values of compliance constants do not depend on the coordinate system. The physical meaning of compliance constants is deduced from their definition as the partial second derivative of the potential energy due to an external force:

$$
C_{\mathrm{ij}}=\frac{\partial^{2} E}{\partial f_{\mathrm{i}} \partial f_{\mathrm{j}}}
$$

The $\mathrm{H} \cdots \mathrm{O} / \mathrm{N}$ and $\mathrm{M}^{+} \ldots \mathrm{O}$ distances (where $\mathrm{O} / \mathrm{N}$ are the $\mathrm{H}$-bond acceptor and the oxygen coordinating with the metal ion $\mathrm{M}^{+}$) were used as internal coordinates for the calculation of the $C_{\mathrm{ij}}$ constants. In other words, compliance constants measure the displacement of an internal coordinate resulting from a unit force acting on it. As follows from this definition, a lower numerical value of the compliance constant represents a stronger bond. The compliance constants were calculated by using the Compliance 3.0.2 program. $^{43,44}$ It should be noted that we were unable to apply this methodology to evaluate the strengths of the van der Waals contacts between stacked bases 
in the (B4) $)_{2}$ and (B4) $)_{3}$ models. This complication stems from the fact that this methodology requires the calculation of the Hessian for these large structures, which was computationally infeasible in our case.

Finally, the strength and location of the non-covalent interactions in model quadruplex structures was studied using NCI analysis, ${ }^{41,42}$ which is based on the dependence between the reduced electron density gradient $s(r)$ and the $\operatorname{sign}\left(\lambda_{2}\right) \rho$, where $\lambda_{2}$ is the second eigenvalue of the electron density Hessian and $\rho$ is the electron density. This method allowed us to identify the regions where the non-covalent interactions arise and allowed us to decide if the interactions are stabilizing or not.

\section{Results and discussion}

\subsection{Energetic preferences and structural characteristics of model quadruplex structures}

It is important to note that any nucleobase B that can potentially form artificial G-compatible quadruplex structures should satisfy several requirements: (i) steric compatibility with Gua; (ii) the ability to form stable H-bonded quartets; (iii) feasibility of ion coordination inside the central pore of a quadruplex without major hindrances; (iv) the formation of helical stacks connected by a relaxed sugar-phosphate backbone; (v) the quadruplex formation should be energetically favorable, i.e., the formation energies of quadruplex structures with base $\mathrm{B}$ should be comparable with energies for the corresponding Gua-containing structures. Taking into account these simple criteria, we will examine some geometrical and energetic preferences of xanthine-based model quadruplex structures and compare their properties with guanine-containing models.

We start with a brief comparison of some specific properties of Gua and Xan bases. Both bases have two H-bond accepting and $\mathrm{H}$-bond donating sites. They are also able to form stable Hoogsteen base pairs through two H-bonds, which is important for the stability of base quartets. The partial atomic charges for Gua and Xan monomeric units optimized at the BLYP-D3/def2TZVPP level of theory were estimated by two different methods (Table 1). The charge analysis allowed the following conclusions: (i) the O6 charge values in Gua and Xan bases are rather close, which points out that the O6 of Xan can be a good H-bond acceptor. The slightly lower O6 charge of Xan indicates that this base has an intrinsic tendency to form somewhat weaker coordination bonds with $\mathrm{Na}^{+} / \mathrm{K}^{+}$ions; (ii) the $\mathrm{O} 2$ atom of Xan has a greater negative charge relative to $\mathrm{O} 6$ and thus can be a stronger $\mathrm{H}$-bond acceptor. However, the H-bonding capability

Table 1 Table of atomic charges calculated for Gua and Xan monomeric units (ESP-Kolmann and NBO charges)

\begin{tabular}{lllllll}
\hline & & O6 & H1 & O2 & NH2 & N7/H7 \\
\hline G & ESP & -0.6387 & 0.4153 & & $0.4019 / 0.4060$ & -0.7031 \\
& NBO & -0.6294 & 0.4211 & & $0.4052 / 0.4122$ & -0.4470 \\
& & & & & & \\
X & ESP & -0.6195 & 0.4038 & -0.6618 & & 0.4039 \\
& NBO & -0.6043 & 0.4296 & -0.6246 & & 0.4447
\end{tabular}

of both oxygens can vary, being influenced by the environment (presence of ion(s), solvent, stacking); (iii) the charges of the $\mathrm{H} 1$ atoms are similar in both monomeric units, which indicates a similar degree of polarity of the $\mathrm{H}$-bond donating moieties $\mathrm{N} 1 \mathrm{H}$.

To characterize the steric compatibility of the Gua and Xan bases, we calculated their van der Waals volumes for optimized geometries (Table S1 in the ESI $\dagger$ ) by using the Vega ZZ program. ${ }^{67}$ The close values of these volumes $\left(114.9 \AA^{3}\right.$ for Xan and $116.7 \AA^{3}$ for Gua) imply good steric compatibility of the Gua- and Xan-based quadruplexes. We checked this statement by calculating the van der Waals volumes for higher order Gua- and Xan-containing structures, tetrads B4 and two stacked tetrads (B4) $)_{2}$ with/without ions (Fig. 1 and 2, Fig. S1-S3 in the ESI $\dagger$ ). It turned out that even for two stacked tetrads with $\mathrm{Na}^{+} / \mathrm{K}^{+}$the maximal difference in the volumes of Gua- and Xan-based structures does not exceed 5\% (Table S1, ESI $\dagger$ ). However, it should be noted that the steric complementarity in real Gua- and Xan-containing quadruplexes is also determined by the conformational preferences of their sugar-phosphate backbone, which are not included in our simple models.

To evaluate the energetic preferences of formation of the Gua- and Xan-based structures, we calculated the formation energies (Table S2 in the ESI $\dagger$ ) for the optimized B4, (B4) $)_{2}$, and (B4) $)_{3}$ structures with or without $\mathrm{Na}^{+} / \mathrm{K}^{+}$ion(s). The influence of the environment was taken into account by using the COSMO model. ${ }^{56}$ The obtained results (Table $\mathrm{S} 2, \mathrm{ESI} \dagger$ ) indicate that formation energies for the hollow Gua and Xan B4, (B4) ${ }_{2}$, and (B4) ${ }_{3}$ models $\left(-33 \mathrm{kcal} \mathrm{mol}^{-1},-89 \mathrm{kcal} \mathrm{mol}^{-1},-139 \mathrm{kcal} \mathrm{mol}^{-1}\right.$ for Gua and $-30 \mathrm{kcal} \mathrm{mol}^{-1},-87 \mathrm{kcal} \mathrm{mol}^{-1},-145 \mathrm{kcal} \mathrm{mol}^{-1}$ for Xan B4, (B4) $)_{2}$, and (B4) $)_{3}$ complexes, respectively) are similar. These values are close to those reported in ref. 18. It is interesting that whereas the formation of Gua quartets and two stacked Gua quartets is slightly more favorable, the system of three stacked Xan quartets $(\mathrm{X} 4)_{3}$ appears to be more stable than the $(\mathrm{G} 4)_{3}$. This fact can be rationalized by the more favorable stacking between parallel Xan tetrads. It becomes more pronounced as the number of stacked tetrads increases (see below). However, the addition of $\mathrm{Na}^{+} / \mathrm{K}^{+}$ions has substantially more stabilizing influence on Gua-containing structures vs. Xan-based models, which can be partially explained by the higher negative charge of the $\mathrm{O6}$ atom in Gua (Table 1).

H-bonding, $\pi-\pi$ stacking, and ion-base coordination are considered to be the most important non-covalent interactions that determine the structure of quadruplexes. In this regard, it is important to know to what extent each type of non-covalent interaction contributes to the energetic stability of the DNA quadruplexes. To tackle this question, we tried to estimate the role of the individual contributions for our models (Gua and Xan tetrads, two stacked tetrads, and three stacked tetrads) by means of energy decomposition performed in ADF. ${ }^{58}$ The obtained results (Fig. 3, Table S3, ESI $\dagger$ ) for $(\mathrm{B} 4)_{2}$ suggest that in the case of two stacked tetrads with ions, the H-bonding plays a dominant role in stabilizing the model quadruplex structure (its contribution is around 50\%) whereas stacking and ion coordination make up $10-14 \%$ and $34-41 \%$ of the total 

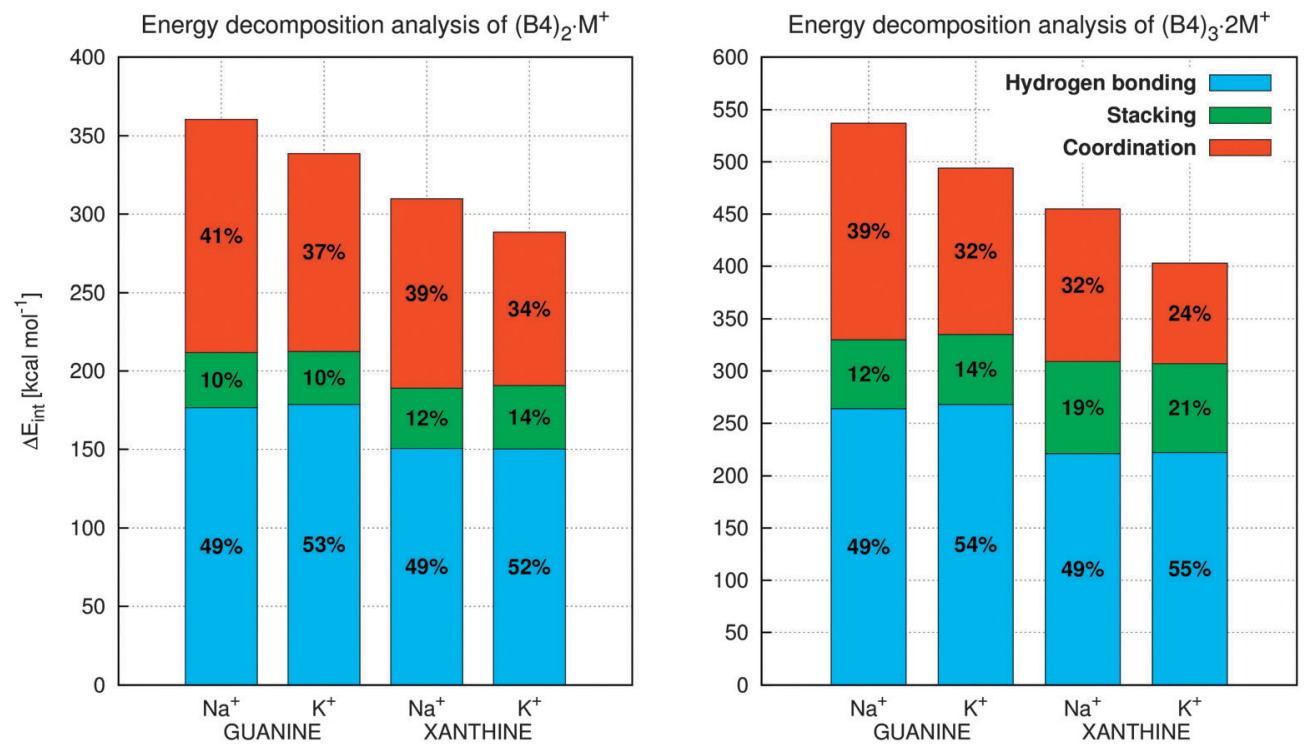

Fig. 3 Relative contributions (in \%) of hydrogen bonding, stacking, and coordination to the internal stability of (B4) $)_{2} \cdot \mathrm{M}^{+}\left(\right.$left) and (B4) $3_{3} \cdot 2 \mathrm{M}^{+}$(right) models. The interaction energies $\Delta E_{\text {int }}$ were obtained by energy decomposition analysis in the ADF ${ }^{58}$ suite of programs at the BLYP-D3/TZP level of theory in vacuo (for a definition of $\Delta E_{\text {int, }}$, see formula (2)). The geometries were optimized at the same level of theory using the COSMO solvent model of water.

interaction energy, respectively. In this context, it is crucial to find out whether these ratios remain the same in the case of real DNA quadruplexes, where more stacked tetrads are present. Energy decomposition analysis of the interaction energies in (B4) $)_{3}$ models with two $\mathrm{Na}^{+} / \mathrm{K}^{+}$ions (Fig. 3, Table S3, ESI $\dagger$ ) suggests that in larger stacks with several ions the $\mathrm{H}$-bonding contribution remains approximately the same $(\sim 50 \%)$, while the balance between coordination and stacking shifts slightly towards the latter due to the repulsion between the cations inside the central channel. For instance, in the $(\mathrm{X} 4)_{3} \cdot 2 \mathrm{~K}^{+}$structure the $\mathrm{H}$-bonding, stacking, and coordination contributions are $55 \%$, $21 \%$, and $24 \%$, respectively. The results of energy decomposition analysis for these simple models (two stacked tetrads and three stacked tetrads with one and two cations, respectively) can, in principle, be extrapolated to larger DNA quadruplex stacks since every tetrad in DNA quadruplexes interacts with 2 (for internal tetrads) or 1 (external) neighbor(s), and up to 1 cation can be sandwiched between tetrad layers. Therefore, $\mathrm{H}$-bonding is estimated to contribute approximately $50 \%$ to the internal stability of the DNA quadruplex in the absence of the sugarphosphate backbone (Fig. 3), whereas the stacking and coordination terms are commensurable and correspond to the remaining $\sim 50 \%$ of the internal stability, neglecting any equilibria in the solvent.

As far as geometrical characteristics are concerned, some optimized structures exhibit a noticeable non-planarity. Since base tetrads in real quadruplexes are mainly planar, we tried to evaluate any possible impact of non-planarity on the topologies and energetics of Gua- and Xan-based quadruplex models. First of all, planar structures were built from optimized geometries using the procedure described in the Computational methodology section. Some of the resulting planar structures, namely $\mathrm{G} 4, \mathrm{X} 4,(\mathrm{G} 4)_{2},(\mathrm{X} 4)_{2},(\mathrm{G} 4)_{2} \cdot \mathrm{Na}^{+}$, and $(\mathrm{X} 4)_{2} \cdot \mathrm{Na}^{+}$, were partially optimized with the dihedral angle $\theta$ constrained to $180^{\circ}$
Table 2 Characterization of the tetrad planarity

\begin{tabular}{llllll}
\hline Structure & RMSD & $\Delta E$ & Structure & RMSD & $\Delta E$ \\
\hline $\mathrm{G} 4$ & 0.07 & 0.1 & $\mathrm{X} 4$ & 0.49 & 1.1 \\
$(\mathrm{G} 4)_{2}$ & $0.21 / 0.10$ & 0.3 & $(\mathrm{X} 4)_{2}$ & $0.23 / 0.28$ & 1.8 \\
$(\mathrm{G} 4)_{2} \cdot \mathrm{Na}^{+}$ & $0.08 / 0.09$ & 0.1 & $(\mathrm{X} 4)_{2} \cdot \mathrm{Na}^{+}$ & $0.09 / 0.18$ & 1.2 \\
$(\mathrm{G} 4)_{3} \cdot \mathrm{Na}^{+}$ & $0.05 / 0.08 / 0.08$ & & $(\mathrm{X} 4)_{3} \cdot \mathrm{Na}^{+}$ & $0.24 / 0.22 / 0.11$ & \\
$(\mathrm{G} 4)_{3} \cdot 2 \mathrm{Na}^{+}$ & $0.12 / 0.01 / 0.07$ & & $(\mathrm{X} 4)_{3} \cdot 2 \mathrm{Na}^{+}$ & $0.23 / 0.15 / 0.07$ & \\
$(\mathrm{G} 4)_{3} \cdot \mathrm{K}^{+}$ & $0.11 / 0.05 / 0.05$ & & $(\mathrm{X})_{3} \cdot \mathrm{K}^{+}$ & $0.25 / 0.22 / 0.24$ & \\
$(\mathrm{G} 4)_{3} \cdot 2 \mathrm{~K}^{+}$ & $0.12 / 0.02 / 0.09$ & & $(\mathrm{X} 4)_{3} \cdot 2 \mathrm{~K}^{+}$ & $0.22 / 0.22 / 0.22$ &
\end{tabular}

(for a definition, see Computational methodology). Then the root-mean-square deviations (RMSD) were calculated for individual base quartets in the fully optimized and planar complexes. The latter included six of the above-mentioned partially optimized structures, as well as several selected planarized (B4) ${ }_{3}$ structures, which, however, were not energy minimized in view of the computational limitations. The results (Table 2) show that the xanthine tetrad $\mathrm{X} 4$ and xanthine quartets in $(\mathrm{X} 4)_{3} \cdot 1 \mathrm{Na}^{+}$ and $(\mathrm{X} 4)_{3} \cdot 1 \mathrm{~K}^{+}$structures manifest the greatest deviations from the planar form. In contrast, guanine-containing structures adopt an almost planar conformation with the exception of the lower tetrad in the (G4) $)_{2}$ model. The energy differences $\Delta E$ between the planar and non-planar configurations appeared to be very small. The maximum $\Delta E\left(1.8 \mathrm{kcal} \mathrm{mol}^{-1}\right)$ is observed for the xanthine complex $(\mathrm{X} 4)_{2}$. Therefore, reasonable RMSD values and small energy differences $(\Delta E)$ confirm that fully optimized structures can be considered as very good models of tetrad stacks in DNA quadruplexes.

In addition, twist angles, corresponding to the angular rotation that is needed to get from one base tetrad to the next, were calculated for the optimized geometries (Table 3). In the case of two stacked Gua and Xan tetrads with a hollow cavity - $(\mathrm{G} 4)_{2}$ and $(\mathrm{X} 4)_{2}-$ the values of the twist angles are rather 
Table 3 Equilibrated twist angle for Gua and Xan (B4) $)_{2}$ and $(B 4)_{3}$ models

\begin{tabular}{lll}
\hline Structure & Top twist & Bottom twist \\
\hline$(\mathrm{G} 4)_{2}$ & 31 & \\
$(\mathrm{X} 4)_{2}$ & 29 & \\
$(\mathrm{G} 4)_{2} \cdot 1 \mathrm{Na}^{+} / 1 \mathrm{~K}^{+}$ & $46 / 45$ & \\
$(\mathrm{X} 4)_{2} \cdot 1 \mathrm{Na}^{+} / 1 \mathrm{~K}^{+}$ & $29 / 28$ & $43 / 44$ \\
$(\mathrm{G} 4)_{3} \cdot 1 \mathrm{Na}^{+} / 1 \mathrm{~K}^{+}$ & $40 / 35$ & $44 / 44$ \\
$(\mathrm{G} 4)_{3} \cdot 2 \mathrm{Na}^{+} / 2 \mathrm{~K}^{+}$ & $41 / 46$ & $31 / 29$ \\
$(\mathrm{X} 4)_{3} \cdot 1 \mathrm{Na}^{+} / 1 \mathrm{~K}^{+}$ & $28 / 28$ & $28 / 28$ \\
$(\mathrm{X} 4)_{3} \cdot 2 \mathrm{Na}^{+} / 2 \mathrm{~K}^{+}$ & $28 / 29$ & \\
\hline
\end{tabular}

close $-31^{\circ}$ and $29^{\circ}$, respectively. However, in the Gua (B4) $)_{2}$ and (B4) ${ }_{3}$ models with $\mathrm{Na}^{+} / \mathrm{K}^{+}$ion(s) the values of the twist angles between tetrads exceed $40^{\circ}$, whereas in the corresponding Xan complexes they remain close to $30^{\circ}$. Therefore, $\mathrm{Na}^{+} / \mathrm{K}^{+}$coordination affects the topology of the Gua-containing structures but has only a small effect on the Xan complexes. It should be remarked that in real G-quadruplex DNA structures the twist angle between two adjacent quartets may vary from $\sim 10^{\circ}$ to $\sim 50^{\circ}$ depending on the conformation of the sugar-phosphate backbone and the type of connecting loops (diagonal, lateral, or propeller). ${ }^{68}$

It should also be mentioned that in optimized quartets $\mathrm{Na}^{+}$ adopts a nearly planar position whereas $\mathrm{K}^{+}$is located well above the base plane of the tetrad (the distance from the $\mathrm{K}^{+}$to the mean plane of the tetrad built by the least square fit method is equal to $2.01 \AA$ and $1.97 \AA$ in the case of the $\mathrm{G} 4 \cdot \mathrm{K}^{+}$and $\mathrm{X} 4 \cdot \mathrm{K}^{+}$ structures, respectively). In addition, the guanine and xanthine base quartets in the $\mathrm{G} 4 \cdot \mathrm{K}^{+}$and $\mathrm{X} 4 \cdot \mathrm{K}^{+}$optimized complexes adopt a bent-down saddle-shaped form, in contrast to the planar tetrads in the $\mathrm{G} 4 \cdot \mathrm{Na}^{+}$and $\mathrm{X} 4 \cdot \mathrm{Na}^{+}$structures. These facts agree well with the previous results. ${ }^{15,18,20,27}$

However, in the (B4) $)_{2}$ and (B4) $)_{3}$ models both $\mathrm{Na}^{+}$and $\mathrm{K}^{+}$ cations are sandwiched between two tetrad planes. In the $(\mathrm{G} 4)_{3} \cdot 2 \mathrm{Na}^{+}$complex the distance between the two $\mathrm{Na}^{+}$cations is $3.50 \AA$, the corresponding distance between the two $\mathrm{K}^{+}$ions in $(\mathrm{G} 4)_{3} \cdot 2 \mathrm{~K}^{+}$is equal to $3.57 \AA$. As far as the $(\mathrm{X} 4)_{3} \cdot 2 \mathrm{Na}^{+}$and $(\mathrm{X} 4)_{3} \cdot 2 \mathrm{~K}^{+}$structures are concerned, the distances between the two metal ions are $4.04 \AA$ and $3.76 \AA$, respectively. The longer $\mathrm{Na}^{+} \cdots \mathrm{Na}^{+} / \mathrm{K}^{+} \cdots \mathrm{K}^{+}$distances in the Xan-containing $(\mathrm{X} 4)_{3} \cdot 2 \mathrm{M}^{+}$ models as compared to those containing Gua, $(\mathrm{G} 4)_{3} \cdot 2 \mathrm{M}^{+}$, are evidence that the repulsion between the two $\mathrm{Na}^{+} / \mathrm{K}^{+}$ions inside the cavity is stronger in the case of the former models. Thus, the Gua-containing quadruplexes have a somewhat greater intrinsic propensity to coordinate monovalent cations.

It is noteworthy that Gua and Xan-containing (B4) ${ }_{3}$ systems are characterized by almost the same diameter of the central channel (pore). For instance, in both the $(\mathrm{G} 4)_{3} \cdot 2 \mathrm{~K}^{+}$and the $(\mathrm{X} 4)_{3} \cdot 2 \mathrm{~K}^{+}$structures the distance between opposite $\mathrm{O} 6$ atoms is $\sim 4.60 \AA$ in the central tetrad and $\sim 4.78 \AA$ in the upper and lower tetrads (the corresponding distances for the $(\mathrm{G} 4)_{3} \cdot 2 \mathrm{Na}^{+}$ and $(\mathrm{X} 4)_{3} \cdot 2 \mathrm{Na}^{+}$models are $4.43 \AA$ and $\left.\sim 4.52 \AA\right)$. So, the pore diameter is rather affected by the nature of coordinating ions (e.g., $\mathrm{K}^{+}$-containing models are characterized by a larger diameter as compared to systems containing $\mathrm{Na}^{+}$) than by the nature of the base (Gua and Xan). This fact serves as an additional argument for the compatibility of Gua- and Xanbased DNA quadruplexes.

\subsection{H-bonding in Gua and Xan models}

To elucidate the H-bonding in model DNA quadruplexes, we applied several independent methods including energy decomposition analysis (EDA), electron density topological analysis based on Quantum Theory of Atoms in Molecules (QTAIM), ${ }^{38}$ NBO analysis, ${ }^{39}$ and compliance constant theory. ${ }^{43-45}$ First, we resorted to EDA calculations (Table 4), which enable arbitrarily selecting two or more regions within a molecule or a complex, and decomposed the interaction energy between them into four parts: an electrostatic term $\Delta V_{\text {elstat }}$, the Pauli repulsion of electron shells $\Delta E_{\text {Pauli }}$, the orbital interaction $\Delta E_{\mathrm{oi}}$, and the dispersion contribution $\Delta E_{\text {disp. }}$. First, the simplest models - the H-bonded Hoogsteen base pairs $\mathrm{Gua}_{2}$ and $\mathrm{Xan}_{2}$ - were analyzed (Table 4). The interaction energy for the latter pair $\left(-19.06 \mathrm{kcal} \mathrm{mol}^{-1}\right)$ is noticeably greater than for $\mathrm{Gua}_{2}\left(-16.14 \mathrm{kcal} \mathrm{mol}^{-1}\right)$. However, when two base pairs are combined to form a tetrad, the G-tetrad is much more stabilizing $\left(-55.95 \mathrm{kcal} \mathrm{mol}^{-1}\right)$ than the xanthine tetrad $\left(-38.94 \mathrm{kcal} \mathrm{mol}^{-1}\right)$. This is in agreement with the reported H-bond cooperativity in G-tetrads, which originates from the different $\mathrm{H}$-bonding mechanisms in both tetrads and the different $\mathrm{H}$-bond directions. ${ }^{18}$ The energy decomposition analysis indicates a high degree of covalency for the hydrogen bonds in the base pairs and the tetrads. The relative contributions of the orbital interactions in $\mathrm{Gua}_{2}$ and $\mathrm{Xan}_{2}(-15.76$ and $\left.-18.93 \mathrm{kcal} \mathrm{mol}^{-1}\right)$ are almost equal to the total interaction energies (-16.14 and $-19.06 \mathrm{kcal} \mathrm{mol}^{-1}$, respectively). Thus, the orbital interactions play a crucial role in the formation of $\mathrm{H}$-bonds since the pure electrostatic contributions $(-24.34 \mathrm{kcal}$ and $-25.93 \mathrm{kcal} \mathrm{mol}^{-1}$ for $\mathrm{Gua}_{2}$ and $\mathrm{Xan}_{2}$, respectively) would not even compensate for the destabilizing Pauli repulsion contributions (28.64 and $30.17 \mathrm{kcal} \mathrm{mol}^{-1}$, respectively). This fact also holds true in the case of base quartets.

QTAIM analysis of the individual interactions in all B4 and $(\mathrm{B} 4)_{2}$ models was performed (Table S4 in the ESI $\dagger$ ). We did not consider $(\mathrm{B} 4)_{3}$ models for this type of analysis because (B4) complexes with ions include, in principle, all three basic types of non-covalent interactions between bases (H-bonding, $\pi-\pi$ stacking, and ion coordination) that arise in DNA quadruplexes. Table S4 (ESI $\dagger$ ) summarizes the results of QTAIM and geometric analyses by including the types of interaction, the numbers, and the ranges (from the minimal to maximal value) for BCP and geometrical characteristics.

Detailed QTAIM and geometric analyses of individual H-bonds and ion-base coordination interactions in tetrad models (Table S4, $\mathrm{ESI} \dagger$ ) lead to the following observations: (i) in the G4 tetrad the $\mathrm{N} 1 \mathrm{H} \cdots \mathrm{O} 6$ hydrogen bond is noticeably stronger than $\mathrm{N} 2 \mathrm{H} \cdots \mathrm{N} 7$, whereas in the $\mathrm{X} 4$ structure both types of $\mathrm{H}$-bond $(\mathrm{N} 1 \mathrm{H} \cdots \mathrm{O} 6$ and $\mathrm{N} 7 \mathrm{H} \cdots \mathrm{O} 2$ ) are characterized by close energy values; (ii) the coordination of a metal ion $\mathrm{M}^{+}\left(\mathrm{M}^{+}=\mathrm{Na}^{+}, \mathrm{K}^{+}\right)$weakens the internal $\mathrm{N} 1 \mathrm{H} \cdots \mathrm{O} 6$ hydrogen bond in both tetrads, however, this effect is more pronounced for the Gua tetrads; (iii) the H-bonding angles correlate with the $\mathrm{H}$-bond energy, i.e., larger values of H-bond angle (Table S4, ESI $\dagger$ ) correspond to stronger bonds. 
Table 4 Energy decomposition analysis (EDA) of interaction energies $\Delta E_{\text {in }}$ between different regions of Gua and Xan-based quadruplex models. Model regions were chosen in a way that allows separating the contributions of the different types of non-covalent interactions. The optimization of the geometry and subsequent EDA were performed at the BLYP-D3/TZP level of theory. The energy unit is kcal mol ${ }^{-1}$

\begin{tabular}{|c|c|c|c|c|c|c|c|c|}
\hline Base & Type of non-covalent interaction & Model/optimized structure ${ }^{a}$ & $\Delta E_{\mathrm{oi}}$ & $\Delta E_{\text {Pauli }}$ & $\Delta V_{\text {elstat }}$ & $\Delta E_{\text {disp }}$ & $\Delta E_{\text {int }}=\Sigma \Delta E_{\mathrm{i}}$ & $\operatorname{VDD}^{b}$ (ion) \\
\hline \multirow[t]{12}{*}{ G } & \multirow{2}{*}{ H-bonding } & $\mathrm{B}+\mathrm{B} / \mathrm{B}_{2}$ & -15.76 & 28.64 & -24.34 & -4.69 & -16.14 & - \\
\hline & & $\mathrm{B} 2+\mathrm{B} 2 / \mathrm{B} 4$ & -42.47 & 59.57 & -62.41 & -10.64 & -55.95 & - \\
\hline & \multirow[t]{2}{*}{ Stacking } & $\mathrm{B} 4+\mathrm{B} 4 /(\mathrm{B} 4)_{2}$ & -9.27 & 44.71 & -11.97 & -57.23 & -33.76 & - \\
\hline & & $\mathrm{B} 4$ (int) $+2 * \mathrm{~B} 4(\mathrm{ext}) /(\mathrm{B} 4)_{3}$ & -19.50 & 95.94 & -25.41 & -120.77 & -69.74 & - \\
\hline & \multirow[t]{8}{*}{ Ion coordination } & $\mathrm{B} 4+\mathrm{Na}^{+} / \mathrm{B} 4 \cdot \mathrm{Na}^{+}$ & -38.11 & 23.40 & -90.72 & -5.60 & -111.04 & -0.085 \\
\hline & & $(\mathrm{B} 4)_{2}+\mathrm{Na}^{+} /(\mathrm{B} 4)_{2} \cdot \mathrm{Na}^{+}$ & -41.61 & 9.54 & -102.64 & -13.92 & -148.63 & -0.078 \\
\hline & & $(\mathrm{B} 4)_{3}+\mathrm{Na}^{+} /(\mathrm{B} 4)_{3} \cdot 1 \mathrm{Na}^{+}$ & -44.64 & 13.30 & -111.17 & -14.41 & -156.92 & -0.076 \\
\hline & & $(\mathrm{B} 4)_{3} \cdot \mathrm{Na}^{+}+\mathrm{Na}^{+} /(\mathrm{B} 4)_{3} \cdot 2 \mathrm{Na}^{+}$ & -44.47 & 11.40 & -56.64 & -13.82 & -103.53 & -0.082 \\
\hline & & $\mathrm{B} 4+\mathrm{K}^{+} / \mathrm{B} 4 \cdot \mathrm{K}^{+}$ & -29.26 & 23.10 & -70.65 & -7.33 & -84.13 & -0.063 \\
\hline & & $(\mathrm{B} 4)_{2}+\mathrm{K}^{+} /(\mathrm{B} 4)_{2} \cdot \mathrm{K}^{+}$ & -40.55 & 28.29 & -98.86 & -15.04 & -126.16 & -0.058 \\
\hline & & $(\mathrm{B} 4)_{3}+\mathrm{K}^{+} /(\mathrm{B} 4)_{3} \cdot 1 \mathrm{~K}^{+}$ & -44.07 & 32.09 & -104.45 & -14.96 & -131.39 & -0.059 \\
\hline & & $(\mathrm{B} 4)_{3} \cdot \mathrm{K}^{+}+\mathrm{K}^{+} /(\mathrm{B} 4)_{3} \cdot 2 \mathrm{~K}^{+}$ & -42.74 & 32.13 & -52.76 & -16.36 & -79.73 & -0.063 \\
\hline \multirow[t]{12}{*}{$\mathrm{X}$} & \multirow[t]{2}{*}{ H-bonding } & $\mathrm{B}+\mathrm{B} / \mathrm{B}_{2}$ & -18.93 & 30.17 & -25.93 & -4.37 & -19.06 & - \\
\hline & & $\mathrm{B} 2+\mathrm{B} 2 / \mathrm{B} 4$ & -38.34 & 60.40 & -51.87 & -9.13 & -38.94 & - \\
\hline & \multirow[t]{2}{*}{ Stacking } & $\mathrm{B} 4+\mathrm{B} 4 /(\mathrm{B} 4)_{2}$ & -9.38 & 41.91 & -16.41 & -58.14 & -42.02 & - \\
\hline & & $\mathrm{B} 4$ (int) $+2^{*} \mathrm{~B} 4(\mathrm{ext}) /(\mathrm{B} 4)_{3}$ & -19.27 & 87.19 & -33.22 & -119.74 & -85.04 & - \\
\hline & \multirow[t]{8}{*}{ Ion coordination } & $\mathrm{B} 4+\mathrm{Na}^{+} / \mathrm{B} 4 \cdot \mathrm{Na}^{+}$ & -37.76 & 24.79 & -71.05 & -5.51 & -89.53 & -0.080 \\
\hline & & $(\mathrm{B} 4)_{2}+\mathrm{Na}^{+} /(\mathrm{B} 4)_{2} \cdot \mathrm{Na}^{+}$ & -42.53 & 12.51 & -77.43 & -13.20 & -120.65 & -0.078 \\
\hline & & $(\mathrm{B} 4)_{3}+\mathrm{Na}^{+} /(\mathrm{B} 4)_{3} \cdot 1 \mathrm{Na}^{+}$ & -43.42 & 13.36 & -81.75 & -13.84 & -125.65 & -0.078 \\
\hline & & $(\mathrm{B} 4)_{3} \cdot \mathrm{Na}^{+}+\mathrm{Na}^{+} /(\mathrm{B} 4)_{3} \cdot 2 \mathrm{Na}^{+}$ & -43.87 & 16.04 & -30.85 & -14.44 & -73.12 & -0.080 \\
\hline & & $\mathrm{B} 4+\mathrm{K}^{+} / \mathrm{B} 4 \cdot \mathrm{K}^{+}$ & -28.74 & 25.11 & -55.30 & -7.08 & -66.01 & -0.061 \\
\hline & & $(\mathrm{B} 4)_{2}+\mathrm{K}^{+} /(\mathrm{B} 4)_{2} \cdot \mathrm{K}^{+}$ & -41.10 & 33.89 & -75.96 & -14.43 & -97.59 & -0.060 \\
\hline & & $(\mathrm{B} 4)_{3}+\mathrm{K}^{+} /(\mathrm{B} 4)_{3} \cdot 1 \mathrm{~K}^{+}$ & -42.60 & 34.78 & -79.74 & -14.76 & -102.32 & -0.060 \\
\hline & & $(\mathrm{B} 4)_{3} \cdot \mathrm{K}^{+}+\mathrm{K}^{+} /(\mathrm{B} 4)_{3} \cdot 2 \mathrm{~K}^{+}$ & -41.47 & 34.85 & -24.85 & -16.37 & -47.85 & -0.064 \\
\hline
\end{tabular}

${ }^{a} \mathrm{~B}+\mathrm{B}$ - formation of Hoogsteen base pair from two bases, B2 + B2 - formation of tetrad from two H-bonded Hoogsteen base pairs, B4 + B4 formation of a hollow (B4) $)_{2}$ system from two tetrads, B4 (int) $+2 * B 4$ (ext) - interaction of an internal tetrad with two external tetrads in a threestacked system, B4 $+\mathrm{Na}^{+}$and $\mathrm{B} 4+\mathrm{K}^{+}-$formation of tetrads with a coordinated ion by adding sodium or potassium cations, respectively, $(\mathrm{B} 4)_{2}+\mathrm{Na}^{+}$ and (B4) $)_{2}+\mathrm{K}^{+}$- formation of (B4) $)_{2}$ models with a coordinated ion by adding sodium or potassium cations, $(\mathrm{B} 4)_{3}+\mathrm{Na}^{+}$and (B4) $)_{3}+\mathrm{K}^{+}-$interaction of a stacked three-tetrad system with a coordinated $\mathrm{Na}^{+} / \mathrm{K}^{+}$cation, (B4) $)_{3} \cdot \mathrm{Na}^{+} / \mathrm{K}^{+}+\mathrm{Na}^{+} / \mathrm{K}^{+}$- interaction of a stacked three-tetrad system with Na $/ \mathrm{K}^{+}$ when the other ion is located inside the channel. ${ }^{b}$ Voronoi deformation density of the $\mathrm{Na}^{+} / \mathrm{K}^{+}$cation in a complex.

To take into account the influence of aromatic $\pi-\pi$ stacking on H-bonding in Gua and Xan quartets, the H-bonding in hollow (G4) $)_{2}$ and $(\mathrm{X} 4)_{2}$ structures was characterized using the QTAIM methodology. In the cases of both Gua and Xan models we expected that the energies of the individual $\mathrm{H}$-bonds would increase under the presence of stacking. However, it turned out that for the $(\mathrm{G} 4)_{2}$ structure the energies of the $\mathrm{N} 1 \mathrm{H} \cdots \mathrm{O} 6$ and $\mathrm{N} 2 \mathrm{H} \cdots \mathrm{N} 7$ hydrogen bonds within two stacked tetrads do not substantially change compared to the optimized G4 quartet (Table S4, ESI $\dagger$ ). This can be due to the fact that the individual tetrads in the hollow (G4) $)_{2}$ complex exhibit an appreciable degree of non-planarity (Table 2), which weakens the H-bonds and counterbalances the possibly favorable impact of aromatic $\pi-\pi$ stacking on the H-bond strengths.

To tackle this problem, we compared the H-bond energies in the planarized G4 and (G4) $)_{2}$ structures (Table S4 in the ESI $\dagger$ ). It was found that the sum of the $\mathrm{H}$-bond energies in the $(\mathrm{G} 4)_{2}$ planar structure $\left(151.96 \mathrm{kcal} \mathrm{mol}^{-1}\right.$ according to EML formula (4)) exceeds double the total H-bond energy in G4 (71.69 kcal $\mathrm{mol}^{-1}$ ), which documents that $\pi-\pi$ stacking enhances the H-bonding in Gua quadruplex structures. As far as the corresponding xanthine models are concerned, the strengths of both types of $\mathrm{H}$-bond $(\mathrm{N} 1 \mathrm{H} \cdots \mathrm{O} 6$ and $\mathrm{N} 7 \mathrm{H} \cdots \mathrm{O} 2)$ in the upper and lower tetrads is increased in the $(\mathrm{X} 4)_{2}$ complex relative to the $\mathrm{X} 4$ quartet. Therefore, stacking between parallel tetrad layers has a similar effect on the H-bonding in both the $(\mathrm{G} 4)_{2}$ and (X4) models.
In contrast to the $\mathrm{X} 4 \cdot \mathrm{Na}^{+}$and $\mathrm{G} 4 \cdot \mathrm{Na}^{+}$quartets, the ion coordination in the central cavity of the (G4) $)_{2} \cdot \mathrm{Na}^{+}$and $(\mathrm{X} 4)_{2} \cdot \mathrm{Na}^{+}$ models does not substantially influence the total energy of the $\mathrm{H}$-bonds. This can be explained by the fact that metal ion coordination further increases the tetrad planarity in two-stack complexes, which gives rise to stronger $\mathrm{H}$-bonds and compensates for the weakening of the $\mathrm{N} 1 \mathrm{H}$. . O6 hydrogen bonds due to the polarization of electron density around O6. However, in the case of $(\mathrm{G} 4)_{2} \cdot \mathrm{K}^{+}$and $(\mathrm{X} 4)_{2} \cdot \mathrm{K}^{+}$, the situation is totally different: the $\mathrm{O} 6 \cdots \mathrm{K}^{+}$contacts are stronger than the $\mathrm{O} 6 \cdot \mathrm{Na}^{+}$ (due to the steric requirements of $\mathrm{K}^{+}$, see BCP characteristics), which weakens both types of $\mathrm{H}$-bond $(\mathrm{N} 1 \mathrm{H} \cdots \mathrm{O} 6$ and $\mathrm{N} 7 \mathrm{H} \cdots \mathrm{O} 2)$ and subsequently leads to a decrease in the total H-bond energy. Thus, QTAIM analysis of the local $\mathrm{M}^{+}$...O6 interactions shows that $\mathrm{K}^{+}$tends to bind a bit more strongly to $\mathrm{O} 6$ atoms as compared with $\mathrm{Na}^{+}$cation, although the global effect (the total interaction energies of the ions with the whole system) is also governed by other factors, such as Pauli repulsion and cation interaction with other parts of the system. It should be noted that the presence of $\pi-\pi$ stacking and ion coordination in the $(B 4)_{2}$ models affects the strength of the individual H-bonds as compared to tetrads B4. For instance, whereas in the G4 tetrad the $\mathrm{N} 1 \mathrm{H} \cdots \mathrm{O} 6$ hydrogen bond is stronger than the $\mathrm{N} 2 \mathrm{H} \cdots \mathrm{N} 7$ bond, in $(\mathrm{G} 4)_{2} \cdot \mathrm{Na}^{+}$these two $\mathrm{H}$-bonds are characterized by approximately the same strength (Table S4, ESI $\dagger$ ). The situation is different for the corresponding xanthine-containing models: both of the $\mathrm{H}$-bonds in $\mathrm{X} 4(\mathrm{~N} 1 \mathrm{H} \cdots \mathrm{O} 6$ and $\mathrm{N} 7 \mathrm{H} \cdots \mathrm{O} 2)$ are 
characterized by close energy values, but in $(\mathrm{X} 4)_{2} \cdot \mathrm{Na}^{+}$one of them $(\mathrm{N} 1 \mathrm{H} \cdots \mathrm{O} 6)$ is stronger (Table S4, ESI $\dagger$ ).

All of the H-bonds in Gua and Xan quadruplex model structures manifest a highly directional character, with $\mathrm{AH} \cdots \mathrm{B}$ angles close to $180^{\circ}$ (Table S4, ESI $\dagger$ ). As far as the distances $d_{\mathrm{H} \cdots \mathrm{B}}$ between the hydrogen $(\mathrm{H})$ and the acceptor $\mathrm{B}(\mathrm{B}=\mathrm{O}, \mathrm{N})$ atoms are concerned, they correlate perfectly with the BCP characteristics: smaller $d_{\mathrm{H} \cdots \mathrm{B}}$ distances correspond to greater values of electron density $\rho$, the Laplacian of electron density $\Delta \rho$, and the $\mathrm{H}$-bond energy calculated by using the EML formula. Since the EML formula (4) is known to overestimate H-bond strengths, ${ }^{65,66}$ we resorted to an alternative way of evaluating the $\mathrm{NH} \cdots \mathrm{O}$ hydrogen-bond energies by using the empirical relationship from ref. 66 (for details, see Computational methodology and Table S4 footnote, ESI $\dagger$ ). It turned out that the use of this approach yields much smaller $\mathrm{H}$-bond energy values compared to the EML formula. However, the quantitative trends are well preserved. Therefore, an H-bond energy calculated by the EML formula can be considered as an upper limit of the real H-bond energy.

To further investigate the $\mathrm{H}$-bonding interactions in model DNA quadruplexes, we performed Natural Bond Orbital (NBO) analysis of the H-bonding interactions in model Gua- and Xanbased DNA quadruplexes (Table S5 in the ESI $\dagger$ ). The results show a substantial charge transfer $\mathrm{LP} \rightarrow \mathrm{BD}^{*}$ from one (in the case of nitrogen) or several (in the case of oxygen) Lewis electron lone pairs (LP) of the $\mathrm{H}$-bond acceptor atom to the anti-bonding orbital $\left(\mathrm{BD}^{*}\right)$ corresponding to $\mathrm{H}$-bond donor group $\mathrm{NH}$. The amount of the charge transfer can be expressed in terms of the $\mathrm{BD}^{*}$ orbital populations, which range from 0.045 to 0.064 . Thus, our data unambiguously confirm the important contribution of the covalent component to the $\mathrm{H}$-bonding reported recently. ${ }^{18}$ As far as stabilization energies $E_{2}$ are concerned, they are higher than the $E_{\mathrm{HB}}$ energies calculated by formula (4). However, $E_{2}$ and $E_{\mathrm{HB}}$ agree qualitatively since they both reflect the order of strength for the H-bonds. The correlation coefficient between $E_{2}$ and $E_{\mathrm{HB}}$ is equal to 0.83 (Fig. S4 in the ESI†).

To check the dependence of the H-bond characteristics on the geometry/density functional/basis set type, we obtained optimized geometries of the (G4) $\cdot \mathrm{Na}^{+},(\mathrm{G} 4) \cdot \mathrm{K}^{+},(\mathrm{X} 4) \cdot \mathrm{Na}^{+}$, and (X4) $\cdot \mathrm{K}^{+}$tetrads in Gaussian 09 at the B3LYP-D/6-31++G(d,p) level of theory (Table S6 in the ESI $\dagger$ ). As a result, the geometries of all of the tetrads, except (G4) $\cdot \mathrm{K}^{+}$, appeared to be similar to TURBOMOLE structures. As far as $(\mathrm{G} 4) \cdot \mathrm{K}^{+}$is concerned, the difference between the Gaussian and TURBOMOLE structures lies in the fact that the latter exhibits a much greater degree of non-planarity, with the $\mathrm{K}^{+}$ion located well above the tetrad. In contrast, the Gaussian structure is much more planar and the ion takes a position closer to the $\mathrm{O} 6$ atoms. Comparison of the $\mathrm{H}$-bond energies calculated by the EML formula and the $E_{2}$ NBO stabilization energies of the $\mathrm{LP} \rightarrow \mathrm{BD}^{*}$ donor-acceptor interactions, shows that despite some differences in the absolute values, the qualitative and even quantitative trends are preserved (Tables S4 and S6, ESI $\dagger$ ). The weaker $\mathrm{H}$-bonds in the (G4) $\cdot \mathrm{K}^{+}$ Gaussian structure compared to the related TURBOMOLE complex are explained by the above-mentioned differences in the geometries, especially the smaller distance separating the $\mathrm{K}^{+}$and $\mathrm{O} 6$ atoms, which enfeebles the $\mathrm{N} 1 \mathrm{H} \cdots \mathrm{O} 6$ hydrogen bond strength.

In addition, we estimated the relative strengths of the H-bonds by means of Grunenberg's compliance constant analysis. $^{43-45}$ As a result, the compliance constants for the H-bonds fall into the 2.681 to $7.500 \AA$ per mDyn range (higher values of compliance constants correspond to weaker interactions, Table S6 in the ESI $\dagger$ ). Therefore, the compliance constants reproduce well the energetic order of the H-bonds, which makes them suitable for evaluating the strengths of the non-covalent interactions in DNA quadruplexes.

The NCI plot analysis ${ }^{41,42}$ also allowed us to reveal differences in the H-bonding inside Xan and Gua tetrads $\left[(\mathrm{G} 4)_{2} \cdot \mathrm{Na}^{+}\right.$and $(\mathrm{X} 4)_{2} \cdot \mathrm{Na}^{+}$were taken as examples, Fig. 4]. The blue regions appearing between the hydrogen and the $\mathrm{H}$-bond acceptor indicate the presence of strong interaction. In the case of the $(\mathrm{X} 4)_{2} \cdot \mathrm{Na}^{+}$structure, the blue color is more intense for the $\mathrm{N} 1 \mathrm{H} \cdots \mathrm{O} 6$ as compared to the $\mathrm{N} 7 \mathrm{H} \cdots \mathrm{O} 2$ hydrogen bond (Fig. 4), which points out the greater strength of the $\mathrm{N} 1 \mathrm{H} \cdots \mathrm{O}$ bond. The $\operatorname{sign}\left(\lambda_{2}\right) \rho$ values for the $\mathrm{N} 1 \mathrm{H} \cdots \mathrm{O} 6$ and $\mathrm{N} 7 \mathrm{H} \cdots \mathrm{O} 2$ hydrogen bonds in $(\mathrm{X} 4)_{2} \cdot \mathrm{Na}^{+}$are -0.010 and -0.012 au, respectively. In contrast, in the $(\mathrm{G} 4)_{2} \cdot \mathrm{Na}^{+}$structure both $\mathrm{H}$-bonds with $\operatorname{sign}\left(\lambda_{2}\right) \rho$ values of -0.010 au are manifested by blue isosurfaces of approximately the same intensity, which indicates close H-bond energy values. This result agrees well with the QTAIM data (Table S4, ESI $\dagger$ ). It is worth mentioning that, in addition to H-bonding, green regions, corresponding to

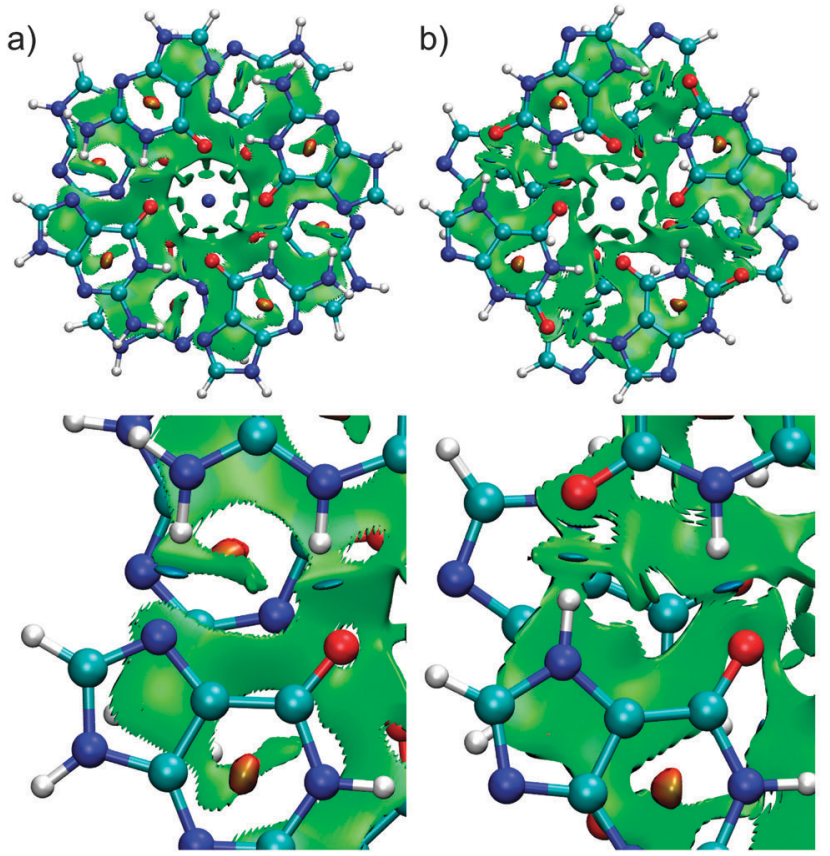

Fig. 4 Total $\mathrm{NCl}$ surfaces (top) of (a) $(\mathrm{G} 4)_{2} \cdot \mathrm{Na}^{+}$and (b) $(\mathrm{X} 4)_{2} \cdot \mathrm{Na}^{+}$structures with details (bottom) highlighting the differences between Gua and Xan in the $\mathrm{H}$-bonding and stacking regions. The $\mathrm{NCl}$ analysis was performed using promolecular densities. The cutoff for the reduced density gradient(s) is 0.4 au and the color scale is $-0.03<\rho<0.03$ au. 
weak (van der Waals) interactions, appear between Xan and Gua base pairs in the tetrads (Fig. 4).

\subsection{Aromatic $\pi-\pi$ stacking}

Aromatic base stacking can be described as a combination of the three most basic contributions to molecular interactions, namely, electrostatic interaction, London dispersion attraction, and short-range repulsion. ${ }^{69}$

To cast light on the stacking in guanine- and xanthine-based model systems we resorted to energy decomposition analysis. For this purpose, the interaction energy between two stacked base tetrads (G4 + G4 and X4 + X4) was estimated and decomposed. It is interesting that in the case of the xanthine tetrads the stacking interaction is more favorable $\left(-42.02 \mathrm{kcal} \mathrm{mol}^{-1}\right)$ compared to the G-tetrads $\left(-33.76 \mathrm{kcal} \mathrm{mol}^{-1}\right)$. This fact should be considered when constructing artificial DNA quadruplexes based on xanthine and its derivatives. Whereas natural G-quadruplexes benefit from a high degree of H-bonding cooperativity, the xanthine tetrads are characterized by stronger $\pi-\pi$ stacking interactions. The decomposition of the interaction energy for Gua and Xan complexes consisting of two stacked tetrads shows that in both cases the contributions of the orbital interaction $(-9.27 \mathrm{kcal}$ in $(\mathrm{G} 4)_{2}$ vs. $-9.38 \mathrm{kcal} \mathrm{mol}^{-1}$ in $\left.(\mathrm{X} 4)_{2}\right)$ and the dispersion term $\left(-57.23 \mathrm{kcal} \mathrm{mol}^{-1}\right.$ in $(\mathrm{G} 4)_{2}$ vs. $-58.14 \mathrm{kcal} \mathrm{mol}^{-1}$ in $\left.(\mathrm{X} 4)_{2}\right)$ are almost equal. The Pauli repulsion that accounts for steric clashes is smaller for the xanthine stack (41.91 kcal mol$\left.{ }^{-1}\right)$ than for the guanine-based model $\left(44.71 \mathrm{kcal} \mathrm{mol}^{-1}\right)$. But the most striking difference lies in the electrostatic part, which is more stabilizing for the xanthine model $\left(-16.41 \mathrm{kcal} \mathrm{mol}^{-1}\right.$ vs. $-11.97 \mathrm{kcal} \mathrm{mol}^{-1}$ in case of $\left.(\mathrm{G} 4)_{2}\right)$. To check whether this tendency holds true for higher order stacked structures (which are more relevant to real DNA quadruplexes), the interaction energies between three stacked tetrads in $(\mathrm{G} 4)_{3}$ and $(\mathrm{X} 4)_{3}$ systems were estimated (Table 4$)$. The interacting regions were chosen in the following way: the first region was the middle (internal) tetrad in a stack interacting with the upper and lower (external) tetrads which formed the second region. As a result, the more favorable stacking of xanthine is even more pronounced in the higher order $(\mathrm{B} 4)_{3}$ model (the interaction energy of the xanthine middle tetrad with two external tetrads is $-85.04 \mathrm{kcal} \mathrm{mol}^{-1}$, whereas the corresponding value for the guanine model is $-69.74 \mathrm{kcal} \mathrm{mol}^{-1}$, Table 4 ). As for the previous (B4) $)_{2}$ model consisting of two stacked quartets, the decisive role in the more pronounced stacking of $(\mathrm{X} 4)_{3}$ belongs to the greater electrostatic attraction and smaller Pauli repulsion. It should be emphasized that the decomposition of the Gua and Xan structures into H-bonding, stacking, and ion coordination contributions (Table S3, ESI $\dagger$ ) indicates that Xan-based model DNA quadruplexes benefit from stacking cooperativity, whereas a similar effect is absent for Gua-containing complexes. For instance, the stacking contribution to the stability of the $(\mathrm{B} 4)_{3} \cdot 2 \mathrm{Na}^{+}$model $\left(-88 \mathrm{kcal} \mathrm{mol}^{-1}\right.$, Table S3, ESI $\left.\dagger\right)$ is noticeably greater than the doubled stacking contribution for the $(\mathrm{B} 4)_{2} \cdot \mathrm{Na}^{+}$complex $\left(-76 \mathrm{kcal} \mathrm{mol}^{-1}\right)$. This $12 \mathrm{kcal} \mathrm{mol}^{-1}$ difference cannot be explained by different degrees of overlap of the stacked tetrads because the twist angles for the (B4) ${ }_{2} \cdot \mathrm{Na}^{+}$and (B4) $)_{3} \cdot 2 \mathrm{Na}^{+}$structures are practically the same (Table 3 ). Therefore, we can conclude that whereas
Gua-containing quadruplexes benefit from H-bond cooperativity, ${ }^{18}$ Xan models are characterized by cooperativity of stacking.

As the second step in the investigation of stacking in model quadruplexes, QTAIM analysis of the individual van der Waals (vdW) contacts arising between nucleobases in parallel tetrad layers of the (B4) $)_{2}$ system, was applied (Fig. S1, ESI $\dagger$ ). These vdW contacts can be responsible for the electrostatic interaction and short-range repulsion components of the stacking. In general, five types of vdW contacts were identified $(\mathrm{C} \cdots \mathrm{C}, \mathrm{N} \cdots \mathrm{N}, \mathrm{N} \cdots \mathrm{C}$, $\mathrm{O} \cdots \mathrm{N}$, and $\mathrm{O} \cdots \mathrm{O}$, Fig. S1, ESI $\dagger$ ). It should be noted that all vdW contacts are characterized by positive values of the electron density Laplacian (Table S4, ESI $\dagger$ ), and can therefore be considered as closed-shell interactions. According to NPA charge analysis (Table S7 in the ESI $\dagger$ ), as expected, two types of vdW contacts $\left(\mathrm{N}^{\delta-} \ldots \mathrm{C}^{\delta+}\right.$ and $\left.\mathrm{C}^{\delta+} \ldots \mathrm{C}^{\delta-}\right)$ are attractive, and the other three are repulsive $\left(\mathrm{O}^{\delta-} \cdots \mathrm{O}^{\delta-}, \mathrm{N}^{\delta-} \cdots \mathrm{N}^{\delta-}\right.$, and $\left.\mathrm{O}^{\delta-} \cdots \mathrm{N}^{\delta-}\right)$.

QTAIM analysis shows that ion coordination to the Gua (B4) ${ }_{2}$ system has a profound influence on the vdW contacts. For instance, the numbers and types of vdW constants are similar in the $(\mathrm{G} 4)_{2} \cdot \mathrm{Na}^{+}$and $(\mathrm{G} 4)_{2} \cdot \mathrm{K}^{+}$structures, which strongly differentiates them from the $(\mathrm{G} 4)_{2}$ model. This can be explained by the fact that ion coordination leads to a significant increase (Table 3 ) in the twist angle (from $\sim 30^{\circ}$ to $\sim 45^{\circ}$ ), which has a strong effect on the vdW contacts formed between parallel tetrads. In (X4) ${ }_{2} \cdot \mathrm{M}^{+}$complexes, on the contrary, the presence of $\mathrm{M}^{+}$in the central channel does not substantially alter the twist angle but increases only the degree of planarity of the stacked tetrads. The latter yields the formation of new intertetrad vdW contacts, e.g., the O6 $\cdots$ O6 in $(\mathrm{X} 4)_{2} \cdot \mathrm{Na}^{+}$, which were absent in the less planar $(\mathrm{X} 4)_{2}$ (Table S5, ESI $\dagger$ ).

In addition to using fully optimized structures, we also performed QTAIM analysis of the vdW contacts in selected planarized tetrads and two stacked tetrads (Table S4 in the ESI $\dagger$ ). Despite the small H-bond energy differences at the level of tetrads, the number, types, and strengths of the vdW interactions in the planar and non-planar $(\mathrm{G} 4)_{2} \cdot \mathrm{Na}^{+}$and $(\mathrm{X} 4)_{2} \cdot \mathrm{Na}^{+}$ structures are very similar (Table S4, ESI $\dagger$ ). This demonstrates that fully optimized two stacked tetrads with ions - $(\mathrm{B} 4)_{2} \cdot \mathbf{M}^{+}-$ can be considered as very good models of planar tetrad stacks in DNA quadruplexes.

We also performed NCI plot analysis employing promolecular densities for the Gua and Xan (B4) $)_{2}$ models with $\mathrm{Na}^{+}$ cation, i.e., $(\mathrm{G} 4)_{2} \cdot \mathrm{Na}^{+}$and $(\mathrm{X} 4)_{2} \cdot \mathrm{Na}^{+}$. Total views and detailed fragments of the NCI surfaces are shown in Fig. 4. It is clear that the area of the green isosurface (corresponding to the stacking) in (X4) ${ }_{2} \cdot \mathrm{Na}^{+}$is greater and its color is more intense than the corresponding surface in $(\mathrm{G} 4)_{2} \cdot \mathrm{Na}^{+}$. This indicates that in $(\mathrm{X} 4)_{2} \cdot \mathrm{Na}^{+}$stacking is more stabilizing due to the higher degree of overlap between the parallel tetrads (determined by the twist angle), and also due to the natural propensity of the xanthine nucleobase to form stronger stacking interactions in DNA quadruplexes. A possible explanation of such a propensity lies in the fact that in addition to the four purine heterocyclic nucleobases, the Gua and Xan tetrads in the (G4) $)_{2} \cdot \mathrm{Na}^{+}$and $(\mathrm{X} 4)_{2} \cdot \mathrm{Na}^{+}$ models (Fig. 4) also contain four pseudoaromatic rings ${ }^{70,71}$ formed by $\mathrm{H}$-bonds between neighboring bases. In the case of the $(\mathrm{X} 4)_{2} \cdot \mathrm{Na}^{+}$ 
structure the effect of stacking between the pseudoaromatic rings in the parallel tetrads is stronger (Fig. $4 \mathrm{~b}$ ) due to the greater energy of the $\mathrm{N} 1 \mathrm{H} \cdots$ O6 hydrogen bond $\left(\sim 12 \mathrm{kcal} \mathrm{mol}^{-1}\right.$ according to the EML formula; the energy of the other $\mathrm{H}$-bond is

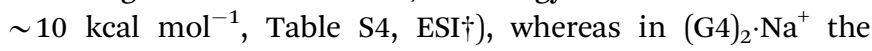
$\mathrm{N} 1 \mathrm{H} \cdots \mathrm{O} 6$ and $\mathrm{N} 2 \mathrm{H} \cdots \mathrm{N} 7$ hydrogen bonds are more or less of equal strength $\left(\sim 10 \mathrm{kcal} \mathrm{mol}^{-1}\right.$, Table S4, ESI $\left.\dagger\right)$. We assume that this difference in $\mathrm{H}$-bonding strength leads to the formation of stronger pseudoaromatic rings in $(\mathrm{X} 4)_{2} \cdot \mathrm{Na}^{+}$and, consequently, contributes to the more favorable stacking between them as evidenced by the extended green NCI surface in this area for the $(\mathrm{X} 4)_{2} \cdot \mathrm{Na}^{+}$model as compared to $(\mathrm{G} 4)_{2} \cdot \mathrm{Na}^{+}$(Fig. 4 , bottom).

\subsection{Ion coordination}

We explored the characteristics of the ion-base coordination interaction by energy decomposition analysis using several models. The simplest model was the Gua/Xan tetrad with coordinating ions $\mathrm{Na}^{+}$and $\mathrm{K}^{+}$, which were considered as two separate regions. The results indicate that these ions tend to bind more strongly to the guanine-containing structures in comparison with the xanthine-based complexes. This difference is explained straightforwardly by the greater negative partial charge of the O6 atom in the guanine base unit (Table 1). In contrast to guanine, the O6 atom in xanthine is less negative due to the presence of the competing electronegative $\mathrm{O} 2$ atom. This leads to $21.51 \mathrm{kcal} \mathrm{mol}^{-1}$ (for $\mathrm{Na}^{+}$) and $18.12 \mathrm{kcal} \mathrm{mol}^{-1}$ (for $\mathrm{K}^{+}$) differences in the metal ion coordination energies between the Gua and Xan tetrads $\mathrm{G} 4 \cdot \mathbf{M}^{+}$and $\mathrm{X} 4 \cdot \mathrm{M}^{+}$(absolute values of the $\mathrm{Na}^{+} / \mathrm{K}^{+}$ion interaction energies with tetrads are listed in Table 4$)$. The corresponding differences between the $(\mathrm{G} 4)_{2} \cdot \mathrm{M}^{+}$and $(\mathrm{X} 4)_{2} \cdot \mathrm{M}^{+}$structures are even more substantial $\left(27.98 \mathrm{kcal}\right.$ and $28.57 \mathrm{kcal} \mathrm{mol}^{-1}$ for the (B4) models with $\mathrm{Na}^{+}$and $\mathrm{K}^{+}$cations, respectively).

In general, the absolute values of the energy of ion binding to model quadruplex structures are higher for $\mathrm{Na}^{+}$than for $\mathrm{K}^{+}$. The reason for this stronger binding of $\mathrm{Na}^{+}$is its smaller ionic radius, which results in a smaller contribution by Pauli repulsion (Table 4). Although DNA quadruplexes were experimentally found to bind preferentially $\mathrm{K}^{+}$ions over $\mathrm{Na}^{+}$, this effect is now attributed to the lower dehydration energy of $\mathrm{K}^{+}$as compared to that of $\mathrm{Na}^{+} \cdot{ }^{72}$ The interaction energy of ions with (B4) $)_{3}$ slightly exceeds the corresponding binding energy for (B4) $)_{2}$. Thus, it may be expected that the ion coordination can become even more favorable in the case of real DNA quadruplexes, where many stacked tetrads are present.

However, we estimated the interaction energy of the ions with Gua and Xan systems $(\mathrm{G} 4)_{3} \cdot 2 \mathrm{M}^{+}$and $(\mathrm{X} 4)_{3} \cdot 2 \mathrm{M}^{+}$when another ion of the same type is present inside the pore (Table 4). As expected, the availability of another $\mathrm{Na}^{+} / \mathrm{K}^{+}$ion in the quadruplex channel drastically decreases the interaction energy of the second ion with the rest of the system due to electrostatic repulsion between the ions (Table 4). The most pronounced decrease is observed in the case of the $(\mathrm{X})_{3} \cdot 2 \mathrm{~K}^{+}$structure. Analysis of the individual coordination energy terms indicates that this type of noncovalent interaction is dominated by the electrostatic term $\Delta V_{\text {elstat }}$ and the orbital interaction contribution $\Delta E_{\text {oi }}$. The latter is commensurable with the electrostatic part, ranging from 30 to
$80 \%$ of $\Delta V_{\text {elstat }}$ For the $(\mathrm{X} 4)_{3} \cdot 2 \mathrm{M}^{+}$system, $\Delta E_{\text {oi }}$ exceeds $\Delta V_{\text {elstat }}$ by more than $10 \mathrm{kcal} \mathrm{mol}^{-1}$. This fact clearly shows that the $\mathrm{Na}^{+} / \mathrm{K}^{+}$ interaction in Gua and Xan quadruplexes cannot be viewed as purely electrostatic, as previously stated. ${ }^{16}$ To provide insight into the process of charge transfer from the DNA quadruplex to the metal ion, we analyzed the values of the Voronoi deformation density (VDD) charges. ${ }^{73}$ The VDD charge $Q_{\mathrm{A}}$ associated with a particular atom directly monitors how much charge flows, due to chemical interaction, out of $\left(Q_{\mathrm{A}}>0\right)$ or into $\left(Q_{\mathrm{A}}<0\right)$ the Voronoi cell of atom $\mathrm{A}$, that is, the region of space that is closer to nucleus A than to any other nucleus. ${ }^{73}$ The obtained data (Table 4) show negative VDD values for the ions, which clearly indicate the direction of the charge transfer (from the quadruplex to the metal ion). It should be mentioned that more negative values of VDD charges are observed for the $\mathrm{Na}^{+}$than for the $\mathrm{K}^{+}$ion in corresponding structures. In general, the values of the VDD charges for $\mathrm{Na}^{+}$ions range from -0.076 to -0.085 for different Gua/Xan quadruplex models, whereas the interval for $\mathrm{K}^{+}$is -0.058 to -0.064 .

It is important to note that this polarization and charge transfer should also be taken into account during the force field parameterization for molecular dynamics (MD) studies of DNA quadruplexes. It seems that the optimal value for the $\mathrm{Na}^{+} / \mathrm{K}^{+}$ charge in MD force fields should be less than +1 . However, the choice of the appropriate value for the $\mathrm{Na}^{+} / \mathrm{K}^{+}$charge in MD force fields will improve only the treatment of the electrostatic term and will not account for any possible quantum effects associated with the charge transfer.

\section{Conclusions}

In this work we performed a comprehensive and systematic investigation of the structural and energetic features of model guanine (Gua)- and xanthine (Xan)-containing DNA quadruplexes. All types of non-covalent interactions and their contributions to the internal quadruplex stability were analyzed. We applied a large arsenal of modern state-of-the-art independent computational techniques, such as Quantum Theory of Atoms in Molecules to identify and characterize individual hydrogen bonding, O6 $\cdots \mathrm{Na}^{+} / \mathrm{K}^{+}$coordination, and van der Waals interactions; Natural Bond Orbital Analysis to study the orbital donor-acceptor interactions of hydrogen bonds; Energy Decomposition Analysis to separate the contributions of hydrogen bonding, $\pi-\pi$ stacking, and ion coordination; Compliance Constant Theory to quantify the relative strengths of hydrogen bonding and coordination contacts; and Non-Covalent Interaction plots to decouple the complex balance of forces that define non-covalent interactions in model DNA quadruplex structures.

The results point to an excellent degree of structural and energetic compatibility between the two types of model quadruplexes. This fact stems from both the structural features (close values of van der Waals volumes, pore radii, geometrical parameters of hydrogen bonds) and the energetic characteristics (the formation energies for the tetrads, the two- and threestacked tetrad models, and the ion binding energies are rather similar). Therefore, xanthine can be considered as an excellent 
candidate for constructing artificial DNA quadruplexes that can be used in different areas of bio- and nanotechnology.

Energetic analysis indicates that hydrogen bonding makes the greatest $(\sim 50 \%)$ contribution to the stability of model DNA quadruplexes, whereas the aromatic base stacking and ion coordination terms are commensurable and account for the remaining $\sim 50 \%$.

From the point of view of non-covalent interactions, Gua- and Xan-based models are somewhat different. Whereas Gua quadruplexes strongly benefit from H-bond cooperativity, ${ }^{18}$ Xan structures are characterized by cooperativity of the stacking. This stems from the fact that, unlike the corresponding Gua complexes, the stacking energies in Xan three-stacked tetrad models, i.e., (B4) ${ }_{3}$, are noticeably greater than the doubled stacking energies in the Xan (B4) $)_{2}$ models consisting of two stacked parallel tetrads. It can thus be expected that in real Xan-based DNA quadruplexes the stabilizing effect of stacking can be even more pronounced as compared to our simple models and can partially compensate for the lack of H-bond cooperativity.

Detailed investigation of the $\mathrm{Na}^{+} / \mathrm{K}^{+}$coordination suggests that despite the dominating electrostatic contribution, this interaction has some degree of covalency and therefore cannot be considered as purely electrostatic.

QTAIM analysis of the non-covalent interactions reveals that the presence of stacking enhances hydrogen bonding in both Gua and Xan structures. Ion coordination deeply affects the non-covalent interactions in Gua models by weakening the hydrogen bonds and altering the twist angle, which changes the character of the van der Waals contacts between parallel stacked tetrads. In contrast, in the Xan models the coordination does not alter the twist angle but modulates the hydrogen bonds and the van der Waals contacts by planarizing the stacked tetrads and enfeebling the internal hydrogen bonds. From this fact it can be inferred that the presence of an ion inside the channel is essential for the formation of planar stacked Xan-based DNA quadruplex structures.

To sum up, xanthine and its derivatives represent very promising candidates for the design of artificial quadruplexes or tetrad-based quadruplex-binding ligands. The molecular design of xanthine derivatives with even more favorable hydrogen bonding, stacking, and ion coordinating properties compared to xanthine and which preserve the steric compatibility with G-quadruplexes should result in improved stability and ionconducting properties of xanthine-derived DNA quadruplexes and quadruplex-binding ligands. This research is currently underway in our laboratory.

\section{Acknowledgements}

Y.P.Y. is deeply grateful to Dr Tymofii Nikolaienko (Kiev National University) for fruitful discussions regarding technical aspects of the calculations. This work was carried out at CEITEC - Central European Institute of Technology with research infrastructure supported by the project CZ.1.05/1.1.00/02.0068 financed from the European Regional Development Fund and in project INBIOR
(CZ.1.07/2.3.00/20.0042) from the European Social Fund and the state budget of the Czech Republic. The access to the CERIT-SC computing and storage facilities provided under the program Center CERIT Scientific Cloud, part of the Operational Program Research and Development for Innovations (CZ.1.05/3.2.00/08.0144), is highly appreciated.

\section{References}

1 P. Hobza and K. Müller-Dethlefs, Non-covalent interactions: Theory and Experiment, RSC Theoretical and Computational Chemistry Series No. 2, RSC Publishing, Cambridge, 2010.

2 E. Frieden, J. Chem. Educ., 1975, 52, 754.

3 A. Warshel, A. Papazyan and P. A. Kollman, Science, 1995, 269, 102.

4 J. L. Huppert and S. Balasubramanian, Nucleic Acids Res., 2007, 35, 406.

5 G. Biffi, D. Tannahill, J. McCafferty and S. Balasubramanian, Nat. Chem., 2013, 5, 182.

6 J. D. Wen, C. W. Gray and D. M. Gray, Biochemistry, 2001, 40, 9300.

7 P. Mohaghegh, J. K. Karow, R. M. Brosh, V. A. Bohr and I. D. Hickson, Nucleic Acids Res., 2001, 29, 2843.

8 H. Sun, A. Yabuki and N. Maizels, Proc. Natl. Acad. Sci. U. S. A., 2001, 98, 12444.

9 E. H. Blackburn, Nature, 1991, 350, 569.

10 L. L. Mantell and C. W. Greider, EMBO J., 1994, 13, 3211.

11 R. D. Gray and J. B. Chaires, Nucleic Acids Res., 2008, 36, 4191.

12 M. Kumar and S. Maiti, Nucleic Acids Res., 2005, 33, 6723.

13 K. E. Riley and P. Hobza, Wiley Interdiscip. Rev.: Comput. Mol. Sci., 2011, $1,3$.

14 J. T. Davis, Angew. Chem., Int. Ed., 2004, 43, 668.

15 T. van Mourik and A. J. Dingley, Chem.-Eur. J., 2005, 11, 6064 .

16 G. Louit, A. Hocquet, M. Ghomi, M. Meyer and J. Sühnel, PhysChemComm, 2003, 6, 1.

17 G. Louit, A. Hocquet, M. Ghomi, M. Meyer and J. Sühnel, PhysChemComm, 2002, 5, 94.

18 C. Fonseca Guerra, H. Zijlstra, G. Paragi and M. Bickelhaupt, Chem.-Eur. J., 2011, 17, 12612.

19 T. van der Wijst, C. Fonseca Guerra, M. Swart, M. Bickelhaupt and B. Lippert, Angew. Chem., Int. Ed., 2009, 48, 3285.

20 A. K. Jissy, U. P. M. Ashik and A. Datta, J. Phys. Chem. C, 2011, 115, 12530.

21 J. Gu and J. Leszczynski, J. Phys. Chem. A, 2000, 104, 6308.

22 M. Meyer, M. Brandl and J. Sühnel, J. Phys. Chem. A, 2001, $105,8223$.

23 M. Meyer and J. Sühnel, J. Biomol. Struct. Dyn., 2003, 20, 507.

24 E. H. Clay and I. R. Gould, J. Mol. Graphics Modell., 2005, 24, 138.

25 C. J. Lech, B. Heddi and A. T. Phan, Nucleic Acids Res., 2013, 41, 2034.

26 G. Paragi, L. Kovács, Z. Kupihár, J. Szolomájer, B. Penke, C. Fonseca Guerra and F. M. Bickelhaupt, New J. Chem., 2011, 35, 119. 
27 J. Szolomájer, G. Paragi, G. Batta, C. Fonseca Guerra, F. M. Bickelhaupt, Z. Kele, P. Pádár, Z. Kupihár and L. Kovács, New J. Chem., 2011, 35, 476.

28 P. Stadlbauer, M. Krepl, T. E. Cheatham III, J. Koča and J. Šponer, Nucleic Acids Res., 2013, 41, 7128.

29 J. Šponer, X. Cang and T. E. Cheatham III, Methods, 2012, 57, 25.

30 P. Akhshi, A. Gregory and G. Wu, J. Phys. Chem. B, 2012, 116, 9363.

31 S. Agrawal, R. P. Ojha and S. Maiti, J. Phys. Chem. B, 2008, 112, 6828.

32 X. Cang, J. Šponer and T. E. Cheatham III, J. Am. Chem. Soc., 2011, 133, 14270.

33 M. Cavallari, A. Calzolari, A. Garbesi and R. Di Felice, J. Phys. Chem. B, 2006, 110, 26337.

34 W. S. Ross and C. C. Hardin, J. Am. Chem. Soc., 1994, 116, 6070.

35 J. Gu and J. Leszczynski, Chem. Phys. Lett., 1999, 311, 209.

36 J. Sagi, J. Biomol. Struct. Dyn., 2013, DOI: 10.1080/07391102. 2013.775074.

37 J. Novotný, P. Kulhánek and R. Marek, J. Phys. Chem. Lett., 2012, 3, 1788.

38 R. F. W. Bader, Atoms in Molecules: A Quantum theory, Oxford University Press, New York, US, 1990.

39 F. Weinhold and C. R. Landis, Valency and Bonding. A Natural Bond Orbital Donor-Acceptor Perspective, Cambridge University Press, UK, 2005.

40 G. te Velde, F. M. Bickelhaupt, E. J. Baerends, C. Fonseca Guerra, S. J. A. van Gisbergen, J. G. Snijders and T. Ziegler, J. Comput. Chem., 2001, 22, 931.

41 E. R. Johnson, S. Keinan, P. Mori-Sanchez, J. Contreras-Garcia, A. J. Cohen and W. Yang, J. Am. Chem. Soc., 2010, 132, 6498.

42 J. Contreras-Garcia, E. R. Johnson, S. Keinan, R. Chaudret, J.-P. Piquemal, D. N. Beratan and W. Wang, J. Chem. Theory Comput., 2011, 7, 625.

43 K. Brandhorst and J. Grunenberg, Chem. Soc. Rev., 2008, 37, 1558.

44 K. Brandhorst and J. Grunenberg, J. Chem. Phys., 2010, 132, 184101.

45 J. Grunenberg and G. Barone, RSC Adv., 2013, 3, 4757.

46 http://www.pdb.org/pdb/home/home.do.

47 Y. Wang and D. J. Patel, J. Mol. Biol., 1993, 234, 1171.

48 E. F. Pettersen, T. D. Goddard, C. C. Huang, G. S. Couch, D. M. Greenblatt, E. C. Meng and T. E. Ferrin, J. Comput. Chem., 2004, 25, 1605.

49 TURBOMOLE V6.3 2011, a development of University of Karlsruhe and Forschungzentrum Karlsruhe $\mathrm{GmbH}$, 1989-2007, TURBOMOLE GmbH, since 2007; available from http://www.turbomole.com.

50 A. D. Becke, Phys. Rev., 1988, 38, 3098.

51 C. Lee, W. Yang and R. G. Parr, Phys. Rev. B: Condens. Matter Mater. Phys., 1988, 37, 785.

52 S. Grimme, J. Antony, S. Ehrlich and H. Krieg, J. Chem. Phys., 2010, 132, 154104.

53 F. Weigend and R. Ahlrichs, Phys. Chem. Chem. Phys., 2005, 7, 3297.
54 T. van der Wijst, C. Fonseca Guerra, M. Swart, F. M. Bickelhaupt and B. Lippert, Angew. Chem., Int. Ed., 2009, 48, 3285.

55 P. Jurečka, J. Šponer, J. Černý and P. Hobza, Phys. Chem. Chem. Phys., 2006, 8, 1985.

56 A. Klamt and G. Schüürmann, J. Chem. Soc., Perkin Trans. 2, 1993, 799.

57 F. Weigend, Phys. Chem. Chem. Phys., 2006, 8, 1057.

58 ADF2012.01, SCM, Theoretical Chemistry, Vrije Universiteit, Amsterdam, The Netherlands, http://www.scm.com.

59 Z. Lu, N. Zhou, Q. Wu and Y. Zhang, J. Chem. Theory Comput., 2011, 7, 4038.

60 T. A. Keith, AIMAll (Version 12.09.23, Professional), 2012, Retrieved from http://www.aim.tkgristmill.com.

61 M. J. Frisch, G. W. Trucks, H. B. Schlegel, G. E. Scuseria, M. A. Robb, J. R. Cheeseman, G. Scalmani, V. Barone, B. Mennucci, G. A. Petersson, H. Nakatsuji, M. Caricato, X. Li, H. P. Hratchian, A. F. Izmaylov, J. Bloino, G. Zheng, J. L. Sonnenberg, M. Hada, M. Ehara, K. Toyota, R. Fukuda, J. Hasegawa, M. Ishida, T. Nakajima, Y. Honda, O. Kitao, H. Nakai, T. Vreven, J. A. Montgomery Jr, J. E. Peralta, F. Ogliaro, M. Bearpark, J. J. Heyd, E. Brothers, K. N. Kudin, V. N. Staroverov, T. Keith, R. Kobayashi, J. Normand, K. Raghavachari, A. Rendell, J. C. Burant, S. S. Iyengar, J. Tomasi, M. Cossi, N. Rega, J. M. Millam, M. Klene, J. E. Knox, J. B. Cross, V. Bakken, C. Adamo, J. Jaramillo, R. Gomperts, R. E. Stratmann, O. Yazyev, A. J. Austin, R. Cammi, C. Pomelli, J. W. Ochterski, R. L. Martin, K. Morokuma, V. G. Zakrzewski, G. A. Voth, P. Salvador, J. J. Dannenberg, S. Dapprich, A. D. Daniels, O. Farkas, J. B. Foresman, J. V. Ortiz, J. Cioslowski and D. J. Fox, Gaussian, Inc., Wallingford CT, 2010.

62 D. Feller, J. Comput. Chem., 1996, 17, 1571-1586.

63 K. L. Schuchardt, B. T. Didier, T. Elsethagen, L. Sun, V. Gurumoorthi, J. Chase, J. Li and T. L. Windus, J. Chem. Inf. Model., 2007, 47, 1045.

64 E. Espinosa, E. Molins and C. Lecomte, Chem. Phys. Lett., 1998, 285, 170.

65 I. Mata, I. Alkorta, E. Espinosa and E. Molins, Chem. Phys. Lett., 2011, 507, 185.

66 T. Y. Nikolaienko, L. A. Bulavin and D. M. Hovorun, Phys. Chem. Chem. Phys., 2012, 14, 7441.

67 A. Pedretti, L. Villa and G. Vistoli, J. Mol. Graphics Modell., 2002, 21, 47.

68 R. V. Reshetnikov, A. M. Kopylov and A. V. Golovin, Acta Nat., 2010, 2, 72.

69 J. Šponer, J. E. Šponer, A. Mládek, P. Jurečka, P. Banáš and M. Otyepka, Biopolymers, 2013, 99, 978.

70 J. J. Dannenberg and R. Rios, J. Phys. Chem., 1994, 98, 6714. 71 A. Dutta, A. D. Jana, S. Gangopadhyay, K. K. Das, J. Marek, R. Marek, J. Brus and M. Ali, Phys. Chem. Chem. Phys., 2011, 13, 15845.

72 N. Hud, F. Smith, F. Anet and J. Feigon, Biochemistry, 1996, 35, 15383.

73 C. Fonseca Guerra, J. W. Handgraaf, E. J. Baerends and F. M. Bickelhaupt, J. Comput. Chem., 2004, 25, 189.

74 S. Neidle, Principles of nucleic acid structure, Elsevier, Amsterdam, 2008. 